\title{
Energy Loss from Transient Eddies due to Lee Wave Generation in the Southern Ocean
}

\author{
LUWEI YANG \\ Institute for Marine and Antarctic Studies, and ARC Centre of Excellence for Climate System Science, \\ University of Tasmania, Hobart, Tasmania, Australia \\ MAXIM NIKURASHIN \\ Institute for Marine and Antarctic Studies, and ARC Centre of Excellence for Climate Extremes, \\ University of Tasmania, Hobart, Tasmania, Australia \\ ANDREW M. HOGG \\ Research School of Earth Sciences, and ARC Centre of Excellence for Climate Extremes, \\ Australian National University, Canberra, Australian Capital Territory, Australia \\ BERNADETTE M. SLOYAN \\ Oceans and Atmosphere, CSIRO, Hobart, Tasmania, Australia
}

(Manuscript received 18 April 2018, in final form 27 September 2018)

\begin{abstract}
Observations suggest that enhanced turbulent dissipation and mixing over rough topography are modulated by the transient eddy field through the generation and breaking of lee waves in the Southern Ocean. Idealized simulations also suggest that lee waves are important in the energy pathway from eddies to turbulence. However, the energy loss from eddies due to lee wave generation remains poorly estimated. This study quantifies the relative energy loss from the time-mean and transient eddy flow in the Southern Ocean due to lee wave generation using an eddy-resolving global ocean model and three independent topographic datasets. The authors find that the energy loss from the transient eddy flow $\left(0.12 \mathrm{TW} ; 1 \mathrm{TW}=10^{12} \mathrm{~W}\right)$ is larger than that from the time-mean flow $(0.04 \mathrm{TW})$ due to lee wave generation; lee wave generation makes a larger contribution $(0.12 \mathrm{TW})$ to the energy loss from the transient eddy flow than the dissipation in turbulent bottom boundary layer $(0.05 \mathrm{TW})$. This study also shows that the energy loss from the time-mean flow is regulated by the transient eddy flow, and energy loss from the transient eddy flow is sensitive to the representation of anisotropy in small-scale topography. It is implied that lee waves should be parameterized in eddy-resolving global ocean models to improve the energetics of resolved flow.
\end{abstract}

\section{Introduction}

The importance of the Southern Ocean in the global circulation and climate is largely attributed to its energetic transient eddy field (Rintoul and Naveira Garabato 2013, and references therein). Transient eddies transport tracers horizontally and momentum vertically, flux heat poleward (e.g., Olbers et al. 2004), modulate changes in the Antarctic Circumpolar Current (ACC) transport (e.g., Meredith and Hogg 2006; Morrison and Hogg 2013), and partly compensate the wind-driven variability in the meridional

Corresponding author: Luwei Yang, luwei.yang@utas.edu.au overturning circulation (MOC) (e.g., Hallberg and Gnanadesikan 2006; Farneti et al. 2010; Abernathey et al. 2011; Dufour et al. 2012; Morrison and Hogg 2013). A good representation of the energetics of the transient eddy field in global ocean general circulation models is essential to accurately simulate the Southern Ocean eddy field and to improve our knowledge of the impacts of the Southern Ocean on the global climate.

The equilibration of the transient eddy field is important because the eddy kinetic energy (EKE) is often used as an indicator of how eddies respond to varying wind stress and therefore regulate the ACC transport and MOC strength. Observations show that the westerly 
wind stress over the Southern Ocean has increased over the last few decades and shifted poleward (Böning et al. 2008; Thompson and Solomon 2002). High-resolution models predict that the increased energy input to the Southern Ocean by wind leads to only small changes in both the ACC transport (Farneti et al. 2010; Dufour et al. 2012; Munday et al. 2013; Hogg et al. 2015) and the Southern Ocean MOC (Hallberg and Gnanadesikan 2006; Farneti et al. 2010; Abernathey et al. 2011; Dufour et al. 2012; Morrison and Hogg 2013). Stronger winds are, however, found to generate a stronger eddy field (Meredith and Hogg 2006; Hogg et al. 2015) indicated by an increased EKE. Eddy energy affects eddyinduced interfacial form stress and meridional eddy fluxes (e.g., Marshall et al. 2012) and therefore regulates the response of the ACC and MOC to strengthening wind stress.

The transient eddy field is a large energy reservoir in the Southern Ocean; the EKE dominates the kinetic energy (KE) field in the Southern Ocean (Ferrari and Wunsch 2009). Transient eddies are generated by the instability of the ACC (e.g., Gill et al. 1974) and lose their energy through several potential mechanisms, including dissipation in the turbulent bottom boundary layer (TBBL) (e.g., Sen et al. 2008; Arbic et al. 2009), interactions with the background internal wave field (e.g., Bühler and McIntyre 2005; Polzin 2008), loss of balance (e.g., Molemaker et al. 2005), and Kelvin wave hydraulic control at large-scale topography (e.g., Hogg et al. 2011). However, the contribution of different mechanisms to the energy loss of transient eddies remains unclear. Nevertheless, it has been argued that eddy-topography interaction, through various mechanisms, dissipates a significant amount of energy from the transient eddy field in the Southern Ocean (e.g., Marshall and Naveira Garabato 2008).

A potential mechanism that extracts energy from transient eddies in the abyssal Southern Ocean is the generation of internal lee waves by the interaction of geostrophic flows and small-scale rough topography. Observations have found elevated turbulent energy dissipation rates $\left(\varepsilon \sim 10^{-8} \mathrm{~W} \mathrm{~kg}^{-1}\right)$ and inferred large mixing rates, indicated by enhanced diffusivity $\left(K_{\rho} \sim 10^{-4} \mathrm{~m}^{2} \mathrm{~s}^{-1}\right)$ with respect to their background values over rough topography in the Southern Ocean (e.g., Polzin et al. 1997; Sloyan 2005; Wu et al. 2011), such as in the Scotia Sea (e.g., Heywood et al. 2002; Naveira Garabato et al. 2004), along the Phoenix Ridge (St. Laurent et al. 2012), in the Drake Passage (e.g., Sheen et al. 2013; Watson et al. 2013), and near the Kerguelen Plateau (e.g., Waterman et al. 2013; Meyer et al. 2015). Enhanced turbulent dissipation and mixing are modulated by the strength of the eddy field downstream of rough topographic features, shown by mooring measurements that have temporal variability, such as near the east Pacific Rise (Liang and Thurnherr 2012) and in the Drake Passage (Sheen et al. 2014). The modulation of the increased dissipation and mixing by the eddy field as well as the roughness of topography implies that these intense turbulent motions are potentially driven by breaking internal lee waves, which are generated by strong bottom flow interacting with rough small-scale topography. The hypothesis that breaking lee waves drive vigorous mixing is supported by observations from the Diapycnal and Isopycnal Mixing Experiment in the Southern Ocean (DIMES) (Naveira Garabato 2010; Meredith 2011) and the Southern Ocean Finestructure project (SO Fine) (Naveira Garabato 2009). Brearley et al. (2013) find a significant temporal correlation between internal wave energy radiation and turbulent dissipation in a region of high EKE over a topographic obstacle in the Drake Passage. Meyer et al. (2016) observe lee waves near the Kerguelen Plateau in the subantarctic/subtropical region and the polar front zone, some of which dissipates near the generation sites while others are advected downstream.

In agreement with observations, Nikurashin and Ferrari (2010a), using idealized numerical simulations representative of the southeast Pacific and Drake Passage, show that estimates of lee wave generation and radiation are sufficient to support local dissipation observed by Naveira Garabato et al. (2004) and Kunze et al. (2006). Nikurashin et al. (2013), using super-high resolution eddy simulations, show that the energy conversion from eddies to smaller-scale motions is catalyzed by rough, small-scale topography. They estimate that about $20 \%$ of the conversion radiates away from the bottom boundary layer and contributes to turbulent dissipation in the ocean interior. Their results highlight the importance of lee waves in the energy pathway from eddies to turbulence.

Global estimates have shown the potential impacts of lee waves on the total geostrophic flow, time-mean flow in the ACC, and water mass transformation. Lee waves have been found to extract between $0.2 \mathrm{TW}(1 \mathrm{TW}=$ $10^{12} \mathrm{~W}$ ) (Nikurashin and Ferrari 2011, hereinafter NF2011) and 0.49 TW (Scott et al. 2011) of energy from the total geostrophic flow globally. Analyzing in situ current meter measurements, Wright et al. (2014) suggest a higher global lee wave generation rate of $0.75 \pm 0.19 \mathrm{TW}$. Lee wave generation has the potential to decelerate the time-mean flow of the ACC by applying a time-mean internal wave drag, which is a significant contributor to the momentum balance of the ocean circulation over the Southern Ocean (Naveira Garabato et al. 2013). The subsequent breaking of lee waves sustains water mass transformation by feeding 
energy into mixing in the deep Southern Ocean (Nikurashin and Ferrari 2013; de Lavergne et al. 2016). Lee waves also affect the momentum and energy of the transient eddy field. The transient eddy field loses its momentum through transient lee wave drag, whose time-mean value is always zero (by definition), whereas the instantaneous momentum loss from the eddy field is generally larger than that from the mean field due to the dependence of lee wave drag on velocity. However, the work done by transient lee wave drag continuously extracts energy from the eddy field, leading to eddy energy loss. The amount of energy loss from the transient eddy field associated with lee wave generation remains unclear and is yet to be estimated.

In this study, we estimate the relative energy loss from the time-mean and transient eddy field in the Southern Ocean $\left(40^{\circ}-65^{\circ} \mathrm{S}\right)$ due to lee wave generation by applying mean-eddy decomposition to modeled velocity fields. Note that lee waves will ultimately be parameterized in global models as momentum terms to affect modeled velocity, although the importance of lee waves for the eddy field is demonstrated in this study mainly using energy diagnostics. The importance of lee wave generation as a process to remove energy from the transient eddy field is evaluated by two comparisons: energy removal from the transient eddy field due to lee wave generation compared with that from the timemean flow and energy loss from the transient eddy field due to lee wave generation compared with that due to the work done by bottom frictional drag in the TBBL. We choose the energy loss in the TBBL for comparison because this eddy energy dissipation route is commonly used in ocean models near the seafloor.

Lee wave generation is sensitive to the anisotropy of the underlying small-scale topography (e.g., Nikurashin and Ferrari 2010a). However, NF2011 assumed that the anisotropy information of small-scale topography is of little importance for the time-mean energy conversion from eddies to lee waves, because eddy velocity vectors span $360^{\circ}$ over an eddy turnover time. In this study, we take advantage of the decomposition to investigate whether anisotropy of small-scale topography is important for the time-mean energy transfer from eddies to lee waves over time.

This paper is organized as follows. In section 2, we describe linear lee wave theory and the mean-eddy decomposition. In section 3 , we introduce the model output and topography dataset used for estimations. In section 4 , we calculate the energy conversion from the total flow to lee waves, and time-mean internal lee wave drag, both of which are compared with results shown in previous studies. We then calculate the energy conversion from the transient eddy field to lee waves and

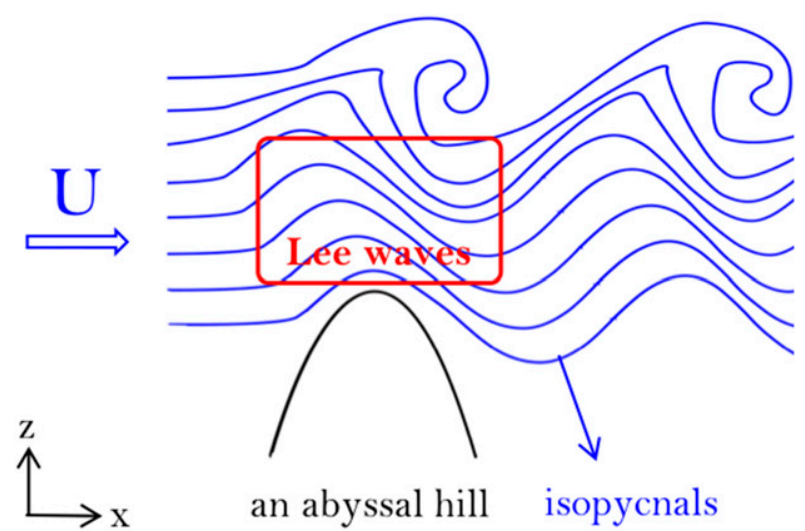

FIG. 1. A schematic of lee wave generation over an abyssal hill.

compare it with eddy energy dissipation in the TBBL. We also discuss the role of anisotropy of small-scale topography in the time-mean energy loss of the transient eddy field due to lee wave generation. In section 5 , a summary of this study and implications of our results are provided.

\section{Theory and method}

\section{a. Internal lee wave generation theory}

Lee waves are generated by quasi-steady geostrophic flow interacting with small-scale topography in a stratified fluid (Fig. 1). Near-bottom flow is lifted by an abyssal hill in the presence of weak stratification. The flow descends downstream of the topography, and the perturbations to the flow velocity and isopycnal depth propagate upward. This upward-propagating perturbation is known as an internal lee wave.

Lee waves radiate upward from generation sites, carrying momentum and energy extracted from the background flow near the seafloor. The radiation of lee waves requires that their intrinsic frequency, $\sigma=\mathbf{k} \cdot \mathbf{u}$ [where $\mathbf{k}=(k, l)$ is the horizontal wavenumber and $\mathbf{u}=(u, v)$ is near-bottom horizontal velocity], is in the range of local inertial $f$ and buoyancy $N$ frequencies (Gill 1982); that is,

$$
|f|<|\sigma|=|\mathbf{k} \cdot \mathbf{u}|<N .
$$

Vertical flux of horizontal momentum and upward energy propagation vanishes where lee waves break. There, their momentum is deposited back to the background flow (Bell 1975). The momentum loss of the background flow associated with radiating lee waves is attributed to lee wave drag. The work done by lee wave drag is the energy transfer from the background flow to lee waves.

Lee wave drag is predicted by linear lee wave theory (Bell 1975; Gill 1982) in the limit of subcritical topography, 
that is, when the topographic slope is smaller than the internal wave slope. It is an integration of all contributions within the internal wave band:

$$
\boldsymbol{\tau}_{\mathrm{LW}}=-\frac{\rho_{o}}{4 \pi^{2}} \int_{-\infty}^{+\infty} \int_{-\infty}^{+\infty} \frac{\mathbf{k}}{|\mathbf{k}|} P(k, l) \sqrt{N^{2}-\sigma^{2}} \sqrt{\sigma^{2}-f^{2}} d k d l
$$

where $\rho_{o}$ is the reference density and $P(k, l)$ is the two dimensional topographic spectrum.

Corrections to the linear theory are required when the topography is critical/supercritical. The subcritical small-scale topography is characterized by steepness parameter $(s=N H / U$, where $N, H$, and $U$ are characteristic values of buoyancy frequency, topographic height, and near-bottom velocity, respectively) that is much smaller than 1 , while the critical/supercritical topography is characterized by $s \geq 1$ (Nikurashin et al. 2014). Nikurashin and Ferrari (2010b) use idealized twodimensional numerical simulations to show that the energy conversion into lee waves increases with steepness parameter before it saturates. The saturation of lee wave generation occurs when the steepness parameter reaches its critical value, above which linear theory overestimates lee wave generation. A correction to the lee wave generation is required when the local steepness parameter is larger than the critical steepness parameter. The critical steepness parameter $s_{c}$ has been explored and tested in various numerical simulations and laboratory experiments, reviewed in Scott et al. (2011). Previous work used the critical steepness parameter as 0.7 (NF2011) and 0.75 (Scott et al. 2011). Here, we take the critical steepness parameter as 0.4 , which is suggested by a process-oriented study (Nikurashin et al. 2014), to represent suppression due to nonlinear blocking and splitting on the energy radiation of lee waves. The correction adopted in this study is

$$
\boldsymbol{\tau}=\boldsymbol{\tau}_{\mathrm{LW}} L^{2}
$$

where

$$
L=\left\{\begin{array}{cll}
1, & \text { if } & s \leq s_{c} \\
s_{c} / s, & \text { if } & s>s_{c}
\end{array}\right.
$$

Our choice of a smaller critical parameter is expected to yield a smaller lee wave generation rate as a larger area of topography will be identified as supercritical and subject to a stronger correction [Eq. (3)].

\section{b. Mean-eddy decomposition}

To estimate the relative energy loss from the time-mean and transient eddy field associated with lee wave generation, we decompose the horizontal velocity $\mathbf{u}=(u, v)$ into its time-mean and transient components $\mathbf{u}=\overline{\mathbf{u}}+\mathbf{u}^{\prime}$, where $\overline{\mathbf{u}}$ is the time-mean Eulerian velocity and $\mathbf{u}^{\prime}$ is the deviation from the time-mean velocity. Lee wave drag is also decomposed into its time-mean and transient components $\boldsymbol{\tau}=\overline{\boldsymbol{\tau}}+\boldsymbol{\tau}^{\prime}$, representing momentum stresses acting on the time-mean and transient eddy flow, respectively, by radiating lee waves. Our time-mean lee wave drag is equivalent to that in Naveira Garabato et al. (2013). Additionally, we derive the form of lee wave drag acting on the eddy flow.

The energy loss of the time-mean and transient eddy flow due to lee wave generation can be expressed as the work done by the corresponding drag component. The energy loss of the time-mean flow is

$$
E_{\text {mean }}=-\overline{\boldsymbol{\tau}} \cdot \overline{\mathbf{u}}
$$

and the time-mean energy loss of the transient eddy flow is

$$
E_{\text {eddy }}=-\overline{\boldsymbol{\tau}^{\prime} \cdot \mathbf{u}^{\prime}}
$$

As lee wave drag is a nonlinear function of total velocity, the eddy velocity has a contribution to the energy loss of the time-mean flow [Eq. (4)]. Energy extraction from the time-mean flow due to lee wave generation, $E_{\text {mean }}=-\overline{\boldsymbol{\tau}(\mathbf{u})} \cdot \overline{\mathbf{u}}=-\overline{\boldsymbol{\tau}\left(\overline{\mathbf{u}}+\mathbf{u}^{\prime}\right)} \cdot \overline{\mathbf{u}}$ [Eq. (4)], is not equal to the lee wave generation by the time-mean flow, $G_{\text {mean }}=-\boldsymbol{\tau}(\overline{\mathbf{u}}) \cdot \overline{\mathbf{u}}$. The interpretation of the difference between $E_{\text {mean }}$ and $G_{\text {mean }}$ is that it is the lee wave field generated by the total flow, rather than by the timemean flow itself, that applies a drag on the time-mean flow. The transient eddy field could also contribute to the time-mean internal wave drag, and therefore the energy loss from the mean flow, through its skewness (i.e., anisotropy) (Naveira Garabato et al. 2013). However, our definition shows that the contribution of the eddy field to the time-mean lee wave drag is finite even in the absence of skewness in the eddy field; the eddy contribution to the energy loss from the time-mean flow arises from the nonlinear dependence of the lee wave drag on the near-bottom velocity.

The contribution of the transient eddy field to the energy loss of the time-mean flow is quantified here as

$$
C_{\text {eddy }}=\left[1-\frac{\boldsymbol{\tau}(\overline{\mathbf{u}}) \cdot \overline{\mathbf{u}}}{\overline{\boldsymbol{\tau}(\mathbf{u})} \cdot \overline{\mathbf{u}}}\right] \times 100 \%
$$

Similarly, the decomposition is also applied to the bottom frictional drag and the energy loss in the TBBL due to the work done by the bottom frictional drag. The bottom frictional drag takes the form of

$$
\boldsymbol{\tau}_{\mathrm{TBBL}}=-\rho_{o} C_{d}|\mathbf{u}| \cdot \mathbf{u},
$$




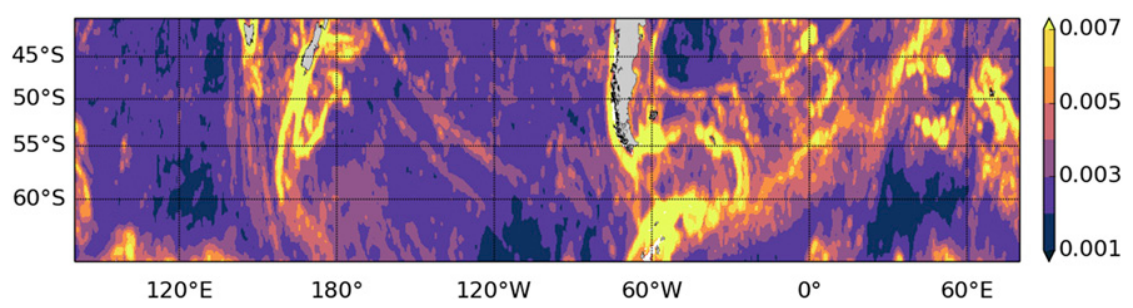

FIG. 2. Quadratic drag coefficient in the Southern Ocean from MOM5-SIS.

where $\rho_{o}$ is the density of the seawater, and $C_{d}$ of $O\left(10^{-3}\right)$ is the drag coefficient.

\section{Data}

\section{a. Bottom velocity and stratification}

We use near-bottom velocity and stratification fields from the MOM5-Sea Ice Simulator (SIS) ocean-sea ice model (Stewart et al. 2017), which is based on the Geophysical Fluid Dynamics Laboratory (GFDL) CM2.6 fully coupled climate model (Griffies et al. 2015). The surface forcing is CORE-II normal year forcing (NYF). The model has $1 / 10^{\circ}$ horizontal resolution and 50 vertical levels. The temporal resolution is 6 hours. We use the final year of output from a 27-yr simulation in this study. The simulated bottom flow in MOM5-SIS is regulated by a parameterized quadratic bottom frictional drag, which follows Eq. (7) with a spatially nonuniform drag coefficient (Fig. 2). The quadratic drag coefficient used in MOM5-SIS varies from 0.001 to 0.007 in the Southern Ocean (see section 20.3.1 in Griffies 2012). The energy dissipation in the TBBL in the current study is computed by using the same parameterization formula and spatially varying drag coefficients as those used in MOM5-SIS and then compared with the offline lee wave estimate. Note that MOM5-SIS neither directly resolves, nor parameterizes, lee wave drag or lee-wave-driven mixing. In other words, the flow simulated by MOM5-SIS is not affected by the generation or breaking of lee waves. We use the model velocity as our best available estimate of the eddy bottom flow in the Southern Ocean and validate these estimates with available observations.

Near-bottom velocity is calculated using a snapshot every fifth day in the final model year and averaged over the deepest $500 \mathrm{~m}$ at each grid point. The sampling frequency of every fifth day has been tested to yield converged results compared with higher sampling frequencies (not shown). Taking averages over the deepest $500 \mathrm{~m}$, following NF2011, considers the generation and propagation of lee waves over a typical vertical wavelength. Our estimates are not sensitive to the averaging depth scale (within the bottom $1000 \mathrm{~m}$ ) because the vertical shear of the horizontal velocity is weak in the deep ocean.

We evaluate the modeled near-bottom velocity by comparing its KE spectra with those from two mooring measurements (Fig. 3). The mooring observations are located within the ACC and near complex topographic regions: the Kerguelen Plateau (SOFine; Naveira Garabato 2009) and Drake Passage (DIMES; Naveira Garabato 2010; Meredith 2011). Both moorings have a current meter within $100 \mathrm{~m}$ of the bottom. Detailed information of mooring measurements are listed in Table 1 . For processing mooring data, we obtain 6-hourly averages of velocity at the deepest instrumented depth and then apply spectral analysis to the time series. Six-hourly averages are computed from the 30- and 15-min observations from SOFine and DIMES, respectively. We then divide the 6-hourly averaged velocity time series into nine segments, which overlap by $50 \%$, using a sliding window whose length is one-fifth of the original time series. Each segment is regarded as an independent sample and used for the spectral analysis. Segments are demeaned, detrended, Hann windowed, FFT-ed, and averaged to get the final spectrum. The power spectrum is shown along with its mean value and 95\% confidence interval (Fig. 3a). For calculating modeled near-bottom velocity, we choose $1^{\circ} \times 1^{\circ}$ grid boxes that correspond to mooring locations. We apply spectral analysis to each modeled velocity time series (final year, 6-hourly, bottom-500-m averaged) in each grid box and average spectra to compare with those from observations. Note that the sampling frequencies we use for model validation and energy estimates are different: the original MOM5-SIS output (final-year 6-hourly time series) is used for model validation to evaluate model near-bottom velocity in the eddy frequency band; finalyear every-fifth-day snapshots are used for the energy calculations as this sampling frequency is tested to yield converged results compared with a higher sampling frequency (e.g., every third day).

MOM5-SIS model output provides a good approximation of near-bottom velocity in the eddy frequency band compared with available mooring measurements (Fig. 3a). KE spectra integrated over the eddy band, 

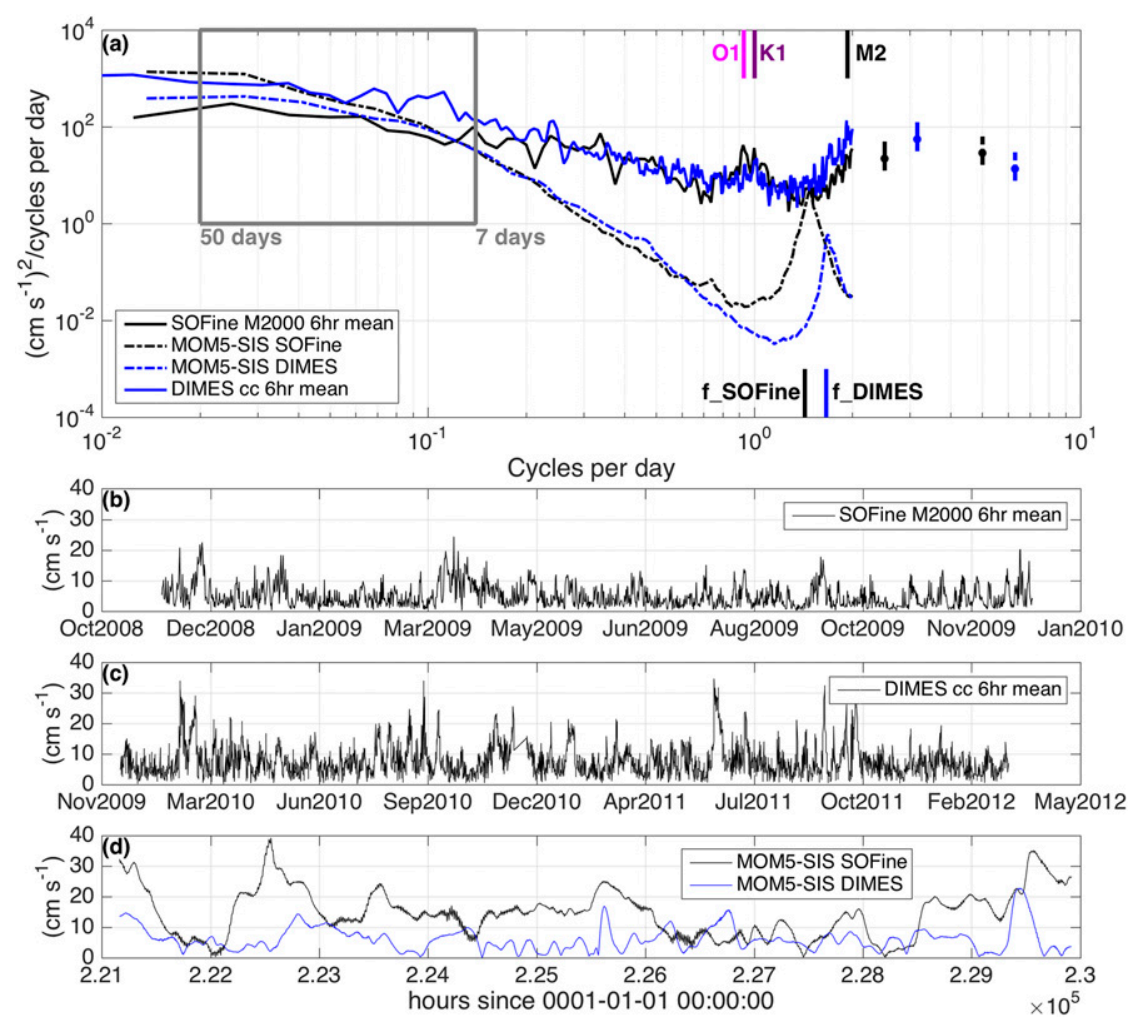

FIG. 3. (a) Spectra of near-bottom KE from two mooring datasets, SOFine M2000 mooring and DIMES Central mooring, and from the corresponding regions in MOM5-SIS. Mooring time series are the 6-hourly mean velocity at the deepest level; modeled time series are the final-year 6-hourly bottom-500-m-averaged velocity. The principal lunar semidiurnal $\mathrm{M}_{2}$ and diurnal $\mathrm{O}_{1}$ and $\mathrm{K}_{1}$ tidal frequencies are marked as well as inertial frequencies for the SOFine and DIMES regions. The gray box marks the approximate eddy frequency band, indicated by the period ranging from 7 to 50 days. The spectra are accompanied with their mean values and $95 \%$ confidence intervals shown on the right. (b) Time series of 6-hourly mean bottom velocity measured by the SOFine M2000 mooring. (c) Time series of 6-hourly mean bottom velocity from the DIMES Central mooring. (d) Time series of the final-year 6-hourly velocity field averaged over the bottom $500 \mathrm{~m}$ at SOFine and DIMES mooring locations from MOM5-SIS.

approximately ranging from 0.02 to 0.14 cycles per day (i.e., period of 7-50 days), from model fields and those from moorings are consistent within a factor of $2-3$. This level of consistency between the velocity field from forward-running eddy-resolving models and that from current meters is reasonable in the deep ocean (Scott et al. 2010).
Strong near-bottom flow is indicated by KE of $O\left(10^{-2}\right) \mathrm{m}^{2} \mathrm{~s}^{-2}$ (Fig. 4a) corresponding to a velocity of $O\left(10^{-1}\right) \mathrm{m} \mathrm{s}^{-1}$. The KE of the total field (Fig. 4a) is decomposed into the mean kinetic energy (MKE) (Fig. 4b) and EKE (Fig. 4c). The EKE dominates the KE over the Southern Ocean, accounting for $72 \%$ of the total KE. The EKE is much larger than the MKE, with an average

TABLE 1. Information of moorings used to validate modeled velocity field.

\begin{tabular}{|c|c|c|c|c|}
\hline & & SOFine M2000 & DIMES (2009) & DIMES (2010) \\
\hline \multirow[t]{2}{*}{ Temporal duration } & Start & 15 Nov 2008 & 10 Dec 2009 & 18 Dec 2010 \\
\hline & End & 15 Jan 2010 & 7 Dec 2010 & 6 Mar 2012 \\
\hline \multicolumn{2}{|c|}{ Sampling frequency } & Every $30 \mathrm{~min}$ & Every 15 min & Every $15 \mathrm{~min}$ \\
\hline \multirow{2}{*}{ Location } & Longitude & $71^{\circ} 51.505^{\prime} \mathrm{E}$ & $57^{\circ} 49.660^{\prime} \mathrm{W}$ & $57^{\circ} 49.717^{\prime} \mathrm{W}$ \\
\hline & Latitude & $46^{\circ} 33.789^{\prime} \mathrm{S}$ & $56^{\circ} 00.710^{\prime} \mathrm{S}$ & $56^{\circ} 00.685^{\prime} \mathrm{S}$ \\
\hline \multicolumn{2}{|c|}{ Water depth (m) } & 1950 & \multicolumn{2}{|c|}{3705} \\
\hline \multicolumn{2}{|c|}{ Instrument depth (m) } & 1869 & 3600 & 3602 \\
\hline
\end{tabular}


a) total

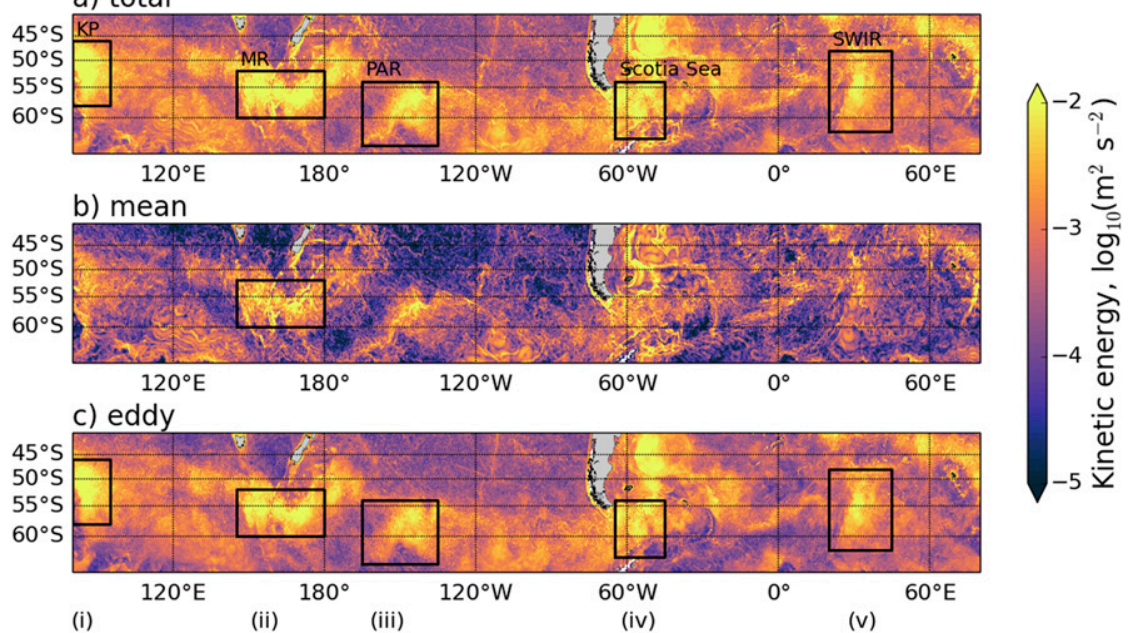

FIG. 4. Bottom-500-m-averaged KE fields. (a) Time-mean total KE, (b) MKE, and (c) timemean EKE in the Southern Ocean from MOM5-SIS. The time-mean field is an average of every-fifth-day snapshots over the final year of MOM5-SIS output. Black boxes in (a) indicate hot spots of total KE, which are located (i) downstream of the KP in the Indian Ocean sector, (ii) near the MR in the Pacific Ocean sector, (iii) near the Udintsev Fracture Zone along the PAR, (iv) in the Scotia Sea, and (v) near the Andrew Bain Fracture Zone along the SWIR. The black box in (b) indicates the area around the Macquarie Ridge where MKE is comparable to EKE. Boxes in (c) are marked as in (a).

ratio of EKE to MKE of 4:1, excluding the values smaller than $10^{-4} \mathrm{~m}^{2} \mathrm{~s}^{-2}$ in both fields. Large total KE is found (i) near the Kerguelen Plateau (KP) in the Indian Ocean sector, (ii) near the Macquarie Ridge (MR) in the Pacific Ocean sector, (iii) near the Udintsev Fracture Zone along the Pacific-Antarctic Ridge (PAR), (iv) in the Scotia Sea, and (v) near the Andrew Bain Fracture Zone along the Southwest Indian Ridge (SWIR). Most of these hot spots can still be found in the eddy field rather than mean field. However, there are some locations where MKE is comparable to EKE (e.g., upstream and downstream of the Macquarie Ridge, marked in Fig. 4b).

We calculate near-bottom stratification from model monthly average potential temperature, salinity, and pressure data. We find and average the stratification in the lower $500 \mathrm{~m}$, consistent with the depth-averaging scale of near-bottom velocity. Near-bottom stratification varies by an order of magnitude in the Southern
Ocean (Fig. 5). The spatially averaged near-bottom stratification in the Southern Ocean is $7.6 \times 10^{-4} \mathrm{~s}^{-1}$. Our estimate of near-bottom stratification from MOM5-SIS model output is consistent in magnitude with previous estimates from observational data (e.g., NF2011; Scott et al. 2011). NF2011 show that $N$ varies from -3.5 to $-2.5 \log _{10}\left(\mathrm{~s}^{-1}\right)$ using the WOCE Hydrographic Atlas. Scott et al. (2011) find that the buoyancy period along the east Pacific Rise, the MidAtlantic Ridge, and the Southwest and Southeast Indian Ridges is between one and two hours [equivalently from -3.9 to $-3.6 \log _{10}\left(\mathrm{~s}^{-1}\right)$ ] using the lowest vertical grid point in the World Ocean Atlas 2009 (WOA2009) climatology. Our estimate of $N$ at those regions is around $-3.0 \log _{10}\left(\mathrm{~s}^{-1}\right)$. The larger $N$ from the model we use with respect to Scott et al. (2011) results from the depth averaging of stratification over the bottom $500 \mathrm{~m}$ as opposed to our deepest $N$ in

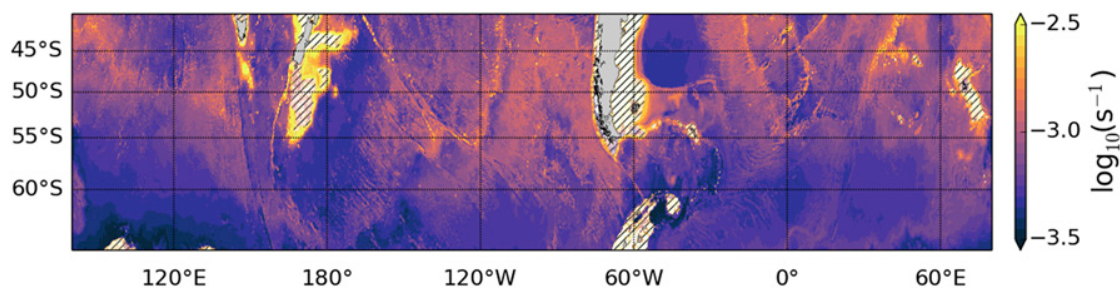

FIG. 5. Bottom-500-m-averaged buoyancy frequency from MOM5-SIS. Shallow area with depth less than $1000 \mathrm{~m}$ is denoted by lightened colors and slash hatching. 
MOM5-SIS being larger than that in WOA2009 used in Scott et al. (2011).

\section{b. Small-scale topography}

The scale of topography that contributes to lee wave generation can be inferred from the radiating condition of lee waves [Eq. (1)]. Substituting characteristic values of $|f| \sim 1 \times 10^{-4} \mathrm{~s}^{-1}, N \sim 1 \times 10^{-3} \mathrm{~s}^{-1}$, and the magnitude of near-bottom geostrophic velocity $|\mathbf{u}| \sim 0.1 \mathrm{~m} \mathrm{~s}^{-1}$, the wavenumber of topography implied in the lee wave generation is in the range of $10^{-3}-10^{-2} \mathrm{~m}^{-1}$, indicating the horizontal wavelength roughly from $600 \mathrm{~m}$ to $6 \mathrm{~km}$. At these small scales, abyssal hills, generally $50-300 \mathrm{~m}$ high, 2-8 km wide, and 10-25 km long (Scott et al. 2011), are the dominant topographic feature that is able to generate lee waves. Note that since MOM5-SIS has $0.1^{\circ}(\sim 10 \mathrm{~km})$ horizontal resolution, the resolved topography has scales of $30-50 \mathrm{~km}$ and larger. These large scales resolved by MOM5-SIS are outside the wave radiating topographic wavelength range (NF2011; Scott et al. 2011) and hence are not needed or used in the calculation. The abyssal hills are not resolved by satellite bathymetry (e.g., Smith and Sandwell 1997) and hence are commonly represented by a two-dimensional anisotropic power spectrum of the form (Goff and Jordan 1988, 1989)

$$
\begin{aligned}
P(k, l)= & 4 \pi \nu \frac{h_{\mathrm{rms}}^{2}}{k_{s} k_{n}}\left[\frac{|\mathbf{k}|^{2}}{k_{s}^{2}} \cos ^{2}\left(\theta-\theta_{s}\right)\right. \\
& \left.+\frac{|\mathbf{k}|^{2}}{k_{s}^{2}} \sin ^{2}\left(\theta-\theta_{s}\right)+1\right]^{-(\nu+1)},
\end{aligned}
$$

where $\nu$ is the spectral slope at high wavenumbers, $h_{\mathrm{rms}}$ is the root-mean-square (rms) topographic height, $k_{s}$ and $k_{n}$ are the characteristic wavenumbers in the strike and normal directions, $\theta_{s}$ is the angle clockwise from true north to the strike direction, and $\theta=\arctan (k / l)$ is the angle clockwise from true north to the wavenumber vector. Spectral slope $\nu$ describes the roll-off of the topographic spectrum when the wavenumber is larger than $\sqrt{k_{s}^{2}+k_{n}^{2}}$. The spectrum is then characterized by the parameters that specify the orientation $\theta_{s}$ and the scale $k_{s}, k_{n}$, the spectral slope $\nu$, and the roughness $h_{\text {rms. }}$. This set of parameters is referred to as topographic parameters hereafter. Topographic spectra [Eq. (8)] statistically describe the characteristics of abyssal hills over a length scale larger than the typical horizontal wavelength of lee waves.

We use three independent topography datasets to estimate the lee wave generation in this work. They are provided by Goff and Arbic (2010, hereinafter GA2010), Goff (2010, hereinafter G2010), and NF2011. GA2010 and G2010 are statistical predictions of topographic parameters based on different methods. Topographic parameters in GA2010 are estimated based on empirical relationships between paleo-spreading rate and abyssal hill roughness, corrected by considering sediment thickness. G2010 derives topographic parameters by applying upward continuation relationships to satellite altimeter observations. G2010 is believed to be slightly better than GA2010 (Scott et al. 2011; Naveira Garabato et al. 2013) because G2010 improves predictions over areas of increased abyssal hill roughness associated with a midocean ridge transition and adds estimates for areas heavily covered by sediments. A more detailed description of and comparisons between GA2010 and G2010 can be found in Scott et al. (2011). NF2011 take single-beam soundings along ship tracks that provide in situ onedimensional topographic sections, process those data under the assumption of isotropy, and simplify the twodimensional topographic spectrum [Eq. (8)] to a onedimensional topographic spectrum:

$$
P_{1 d}(k) \simeq P_{0} k^{-\mu+1},
$$

where $P_{0}$ is the spectral level and $\mu[\mu=2(\nu+1)]$ is the slope at high wavenumbers. NF2011 argue that the lack of anisotropy information matters little, assuming that the geostrophic velocity is dominated by transient eddies that can impinge on abyssal hills at possible directions spanning $360^{\circ}$ over a few eddy turnover times. Therefore, the orientation of abyssal hills, and hence their anisotropy, does not alter the time-mean lee wave energy flux as long as multiple eddy life cycles are included. We test this assumption using anisotropic topography and eddy flows.

Small-scale topographic roughness is on the order of $10-100 \mathrm{~m}$ (Figs. 6a-c). It is readily seen that highroughness, small-scale topography mostly appears along midocean ridges indicated by light colors in depth (Fig. 6d). Specifically, rough small-scale topography is found along the Southeast Indian Ridge (SEIR) south of Tasmania, downstream of Macquarie Ridge (MR) south of Campbell Plateau (CP), to the southwest of the Udintsev Fracture Zone (FZ) along the PAR, in the Drake Passage and Scotia Sea, near the Bouvet Triple Junction along the South American-Antarctic Ridge (SAAR), along the SWIR, and north of the KP. These locations are marked as i-vii in order in Figs. 6a-c.

\section{Results}

\section{a. Total flow}

To compare our results with previously published estimates, we perform three calculations of the energy loss from the total flow due to lee wave generation, using 


\section{a) G2010}
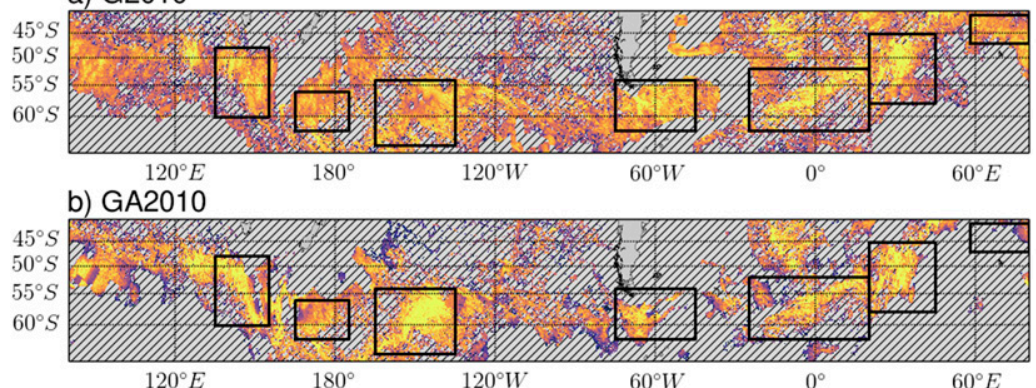

c) NF2011

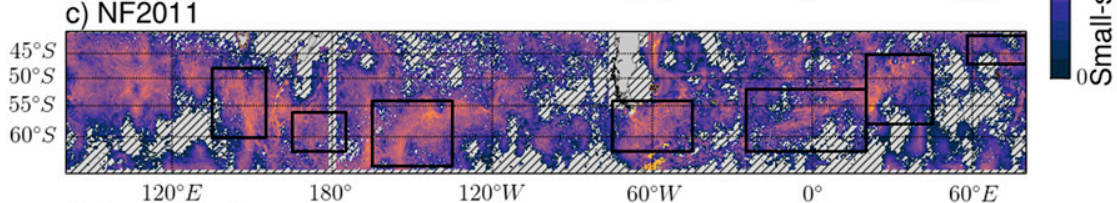

d) Depth $(\mathrm{km})$

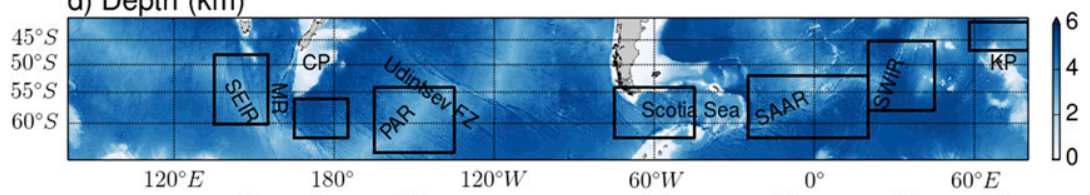

(i) (ii) (iii)

(iv)

(v)

(vi) (vii)

FIG. 6. Maps of topographic roughness of abyssal hills calculated from (a) G2010, (b) GA2010, (c) NF2011, and (d) depth of the Southern Ocean from 1/10 MOM5-SIS. The gray shading with slash hatching in (a)-(c) covers the area where the small-scale topographic parameters are not available and the small-scale roughness is smaller than $1 \mathrm{~m}$. Hot spots marked in boxes are (i) along the SEIR south of Tasmania, (ii) downstream of MR south of CP, (iii) to the southwest of the Udintsev FZ along the PAR, (iv) in the Drake Passage and Scotia Sea, (v) near the Bouvet Triple Junction along the SAAR, (vi) along the SWIR, and (vii) north of the KP.

different topographic datasets. All three calculations are based on the same near-bottom velocity and stratification fields from $1 / 10^{\circ}$ MOM5-SIS. In this study, we use a critical steepness parameter, $s_{c}=0.4$, to correct the linear theory. The steepness parameter in the Southern
Ocean can be as large as $O(10)$ (Fig. 7), and 30\% (for G2010; 25\% for GA2010; and less than 1\% for NF2011) of the area is characterized by a steepness parameter larger than 0.4, which is supercritical and needs correction. Despite the different coverage of data, all three

a) G2010

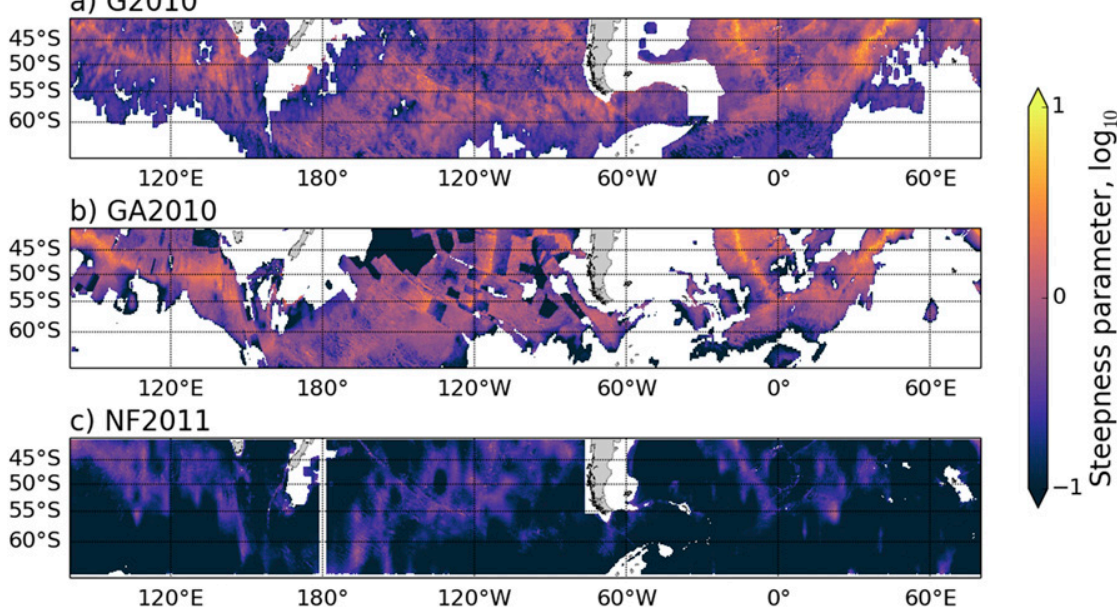

FIG. 7. Critical steepness parameter calculated from near-bottom velocity, stratification, and (a) G2010, (b) GA2010, and (c) NF2011. 

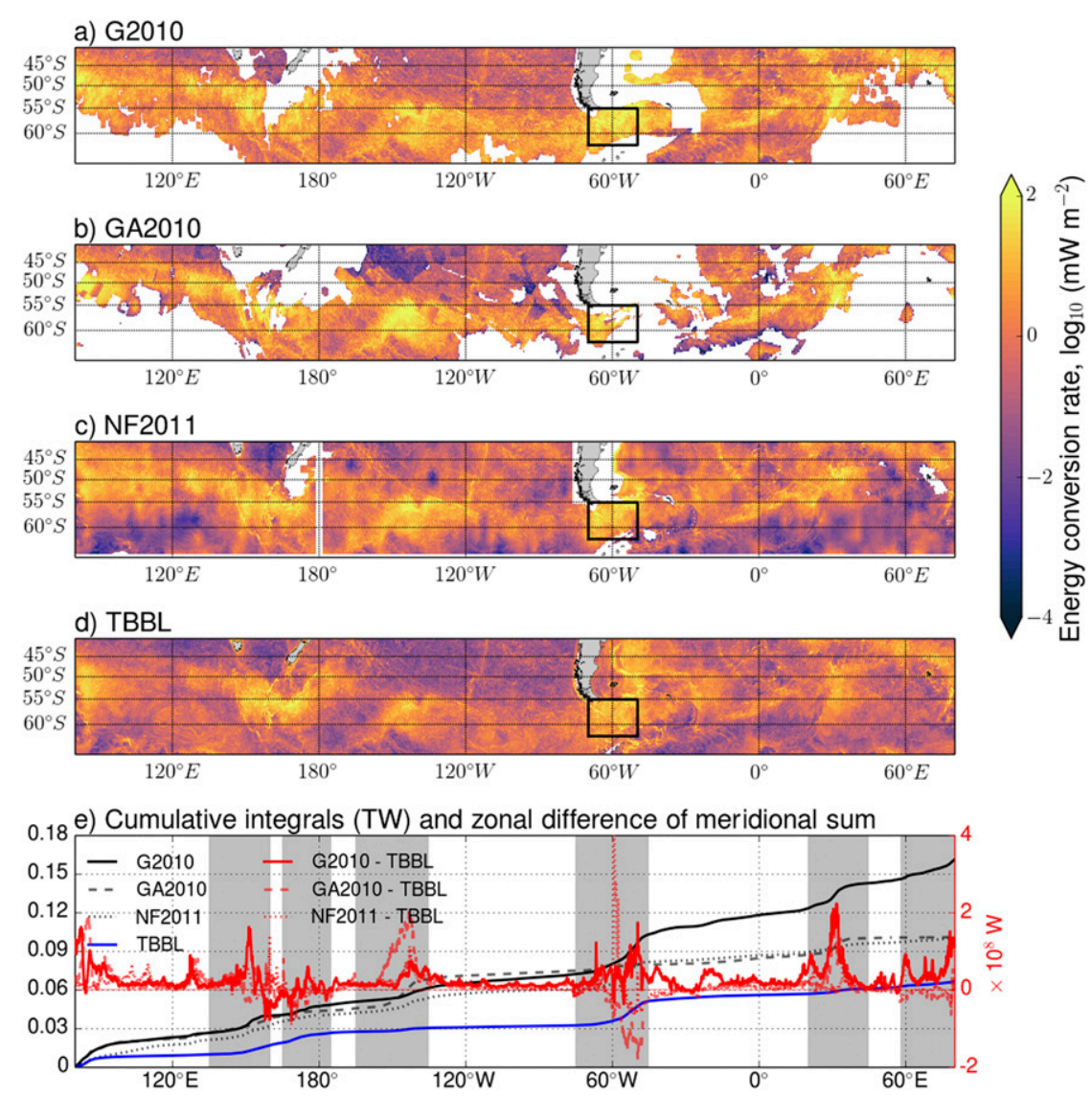

FIG. 8. Energy loss from the total flow associated with lee wave generation and bottom friction in the TBBL. Energy conversion into lee waves is calculated using the near-bottom velocity and stratification fields from MOM5-SIS and topographic spectrum derived from (a) G2010, (b) GA2010, and (c) NF2011. (d) Energy dissipation of the total flow in the TBBL calculated using bottom velocity in MOM5-SIS. (e) Cumulative integrals of the energy loss from the total flow due to lee wave generation are shown as the black lines, and that of energy dissipation in the TBBL is shown as the blue line. Differences between the meridional sum of energy dissipation due to lee wave generation and that in the TBBL are shown as red lines in (e). The gray shadings in (e) correspond to the longitude bands of rough small-scale topography as in Fig. 6 except v. The Drake Passage is marked by black boxes in (a)-(d).

maps of lee wave generation follow a similar spatial pattern (Figs. 8a-c). There are several hot spots characterized by the enhanced lee wave generation rate on the order of $10-100 \mathrm{~mW} \mathrm{~m}^{-2}$. They are located north of Kerguelen Plateau $\left(60^{\circ}-80^{\circ} \mathrm{E}\right)$, downstream of Macquarie Ridge $\left(\sim 170^{\circ} \mathrm{E}\right)$, along the Pacific-Antarctic Ridge $\left(140^{\circ}-160^{\circ} \mathrm{W}\right)$, in the Drake Passage $\left(\sim 60^{\circ} \mathrm{W}\right)$ and along the Southwest Indian Ridge $\left(\sim 30^{\circ} \mathrm{E}\right)$. Their contributions can be seen in the cumulative integrals (Fig. 8e). The improvements in G2010 strongly increase the lee wave generation in the Scotia Sea $\left(\sim 40^{\circ}-60^{\circ} \mathrm{W}\right.$, $\left.55^{\circ}-60^{\circ} \mathrm{S}\right)$ compared with GA2010. The Southern Oceanintegrated energy conversion into lee waves is 0.16 (G2010) and 0.10 TW (GA2010; NF2011).

The spatial distribution of our estimates of lee wave generation from the total flow are consistent with that of similar previous estimates by NF2011 and Scott et al. (2011), but the integrated Southern Ocean estimates are slightly lower. Differences between previous estimates and our estimate come from the modeled near-bottom velocity and stratification fields. For example, the larger $N$ field we use gives a wider range of intrinsic frequency [Eq. (1)]. Note that we also use a smaller critical steepness parameter than Scott et al. (2011), which is expected to produce a lower lee wave generation via Eq. (3) for a fixed local steepness parameter. The Drake Passage-averaged internal lee wave generation rate is 18.0, 11.6, and $8.7 \mathrm{~mW} \mathrm{~m}^{-2}$ corresponding to $\mathrm{G} 2010$, GA2010, and NF2011, respectively, all of which exceed local spatial-mean dissipation rate due to bottom frictional drag, $5.0 \mathrm{~mW} \mathrm{~m}^{-2}$. These local lee wave energy generation rates are also quantitatively comparable 
TABLE 2. Energy extraction rates integrated over the Southern Ocean (default, critical steepness parameter: 0.4; TW).

\begin{tabular}{lcccc}
\hline \hline & Total & Eddy & Mean & Topography \\
\hline Conversion into & 0.161 & $0.122(76 \%)$ & $0.039(24 \%)$ & G2010 \\
lee waves & 0.102 & $0.077(76 \%)$ & $0.025(24 \%)$ & GA2010 \\
& 0.100 & $0.070(70 \%)$ & $0.030(30 \%)$ & NF2011 \\
Dissipation in & 0.066 & $0.048(73 \%)$ & $0.018(27 \%)$ & - \\
TBBL & & & & \\
\hline
\end{tabular}

with a previous local estimate in the Drake Passage using mooring measurements (Brearley et al. 2013).

We also compare the energy extraction from the total flow due to lee wave generation (Figs. 8a-c) with that due to the bottom frictional drag in the TBBL (Fig. 8d). Our estimate of the energy dissipation in the TBBL is consistent with the previous estimates made for the Southern Ocean (e.g., Arbic et al. 2009). Our results show that the differences between the energy loss associated with lee wave generation and that in the TBBL (red lines in Fig. 8e) are mostly coincident with and enhanced by small-scale topographic roughness (gray shading areas in Fig. 8e). These differences arise from the fact that lee wave generation depends on nearbottom velocity and stratification fields as well as small-scale topography, whereas TBBL dissipation is parameterized only as a function of near-bottom velocity field and a spatially varying drag coefficient. The energy conversion into lee waves also occurs across a wider area of the Southern Ocean: the area with a lee wave generation rate higher than $1 \mathrm{~mW} \mathrm{~m}^{-2}$ accounts for 27\% (G2010 and Fig. 8a; 15\% in GA2010 and Fig. 8b; and 23\% in NF2011 and Fig. 8c) of the Southern Ocean while that with a TBBL dissipation higher than $1 \mathrm{~mW} \mathrm{~m}^{-2}$ accounts for $17 \%$ of the Southern Ocean. All three estimates of energy conversion into lee waves have Southern Ocean integrals (Table 2) that are larger than the corresponding estimate for TBBL dissipation from the total flow by a factor of 1.5-2.4. Consistent with previous work (e.g., Naveira Garabato et al. 2013; Nikurashin et al. 2013), our results show that, in the Southern Ocean, lee wave generation makes a larger contribution to the energy loss of the total flow than TBBL processes. Furthermore, the ratio of lee wave generation to TBBL dissipation from the total flow we find agrees well with that calculated from a model with lee wave drag parameterized (Trossman et al. 2016).

\section{b. Mean flow}

We evaluate the time-mean component of lee wave drag $\overline{\boldsymbol{\tau}(\mathbf{u})}$ using three topographic datasets (Figs. 9a-c) and compare it with time-mean bottom frictional drag

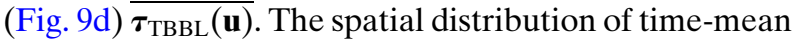
lee wave drag (Figs. 9a-c) follows a similar pattern as compared with the energy loss from the total flow associated with lee wave generation (Figs. 8a-c). Maximum and average time-mean lee wave drag over the Southern Ocean is on the order of 1 and $10^{-2} \mathrm{~N} \mathrm{~m}^{-2}$,

a) G2010

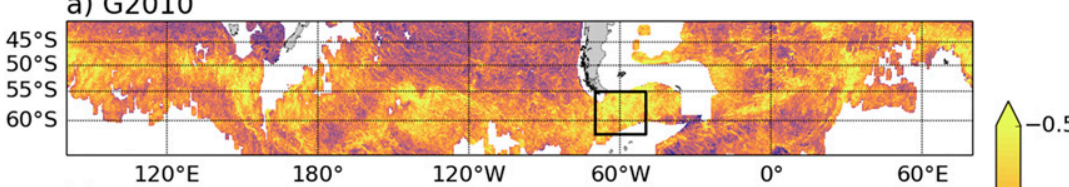

b) GA2010

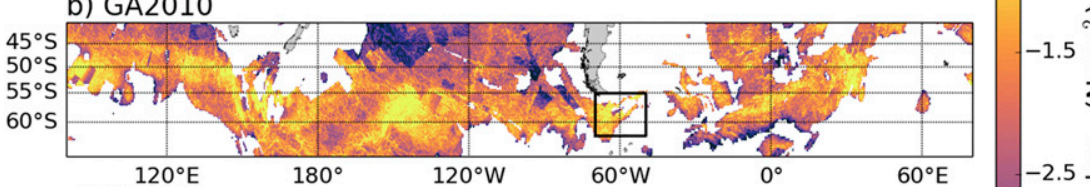

c) NF2011
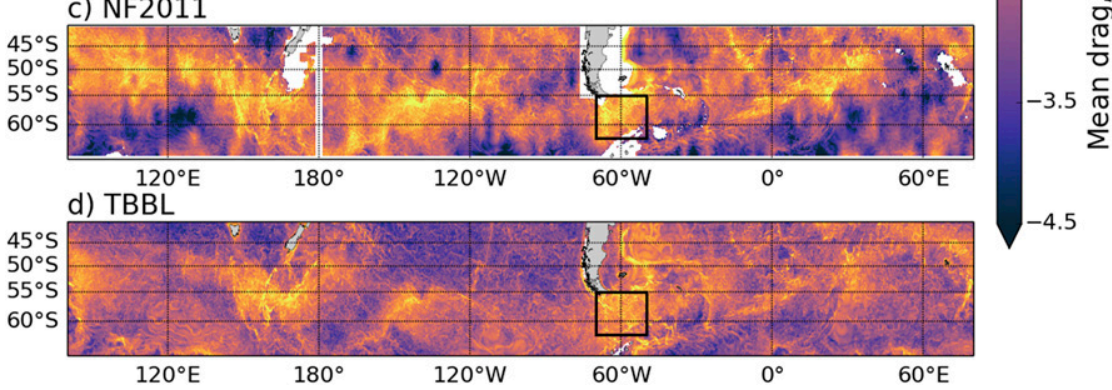

FIG. 9. Time-mean lee wave drag calculated using (a) G2010, (b) GA2010, (c) NF2011, and (d) time-mean bottom frictional drag. Black boxes mark the Drake Passage where the spatialand time-mean lee wave drag and bottom frictional drag are calculated. 
a) G2010

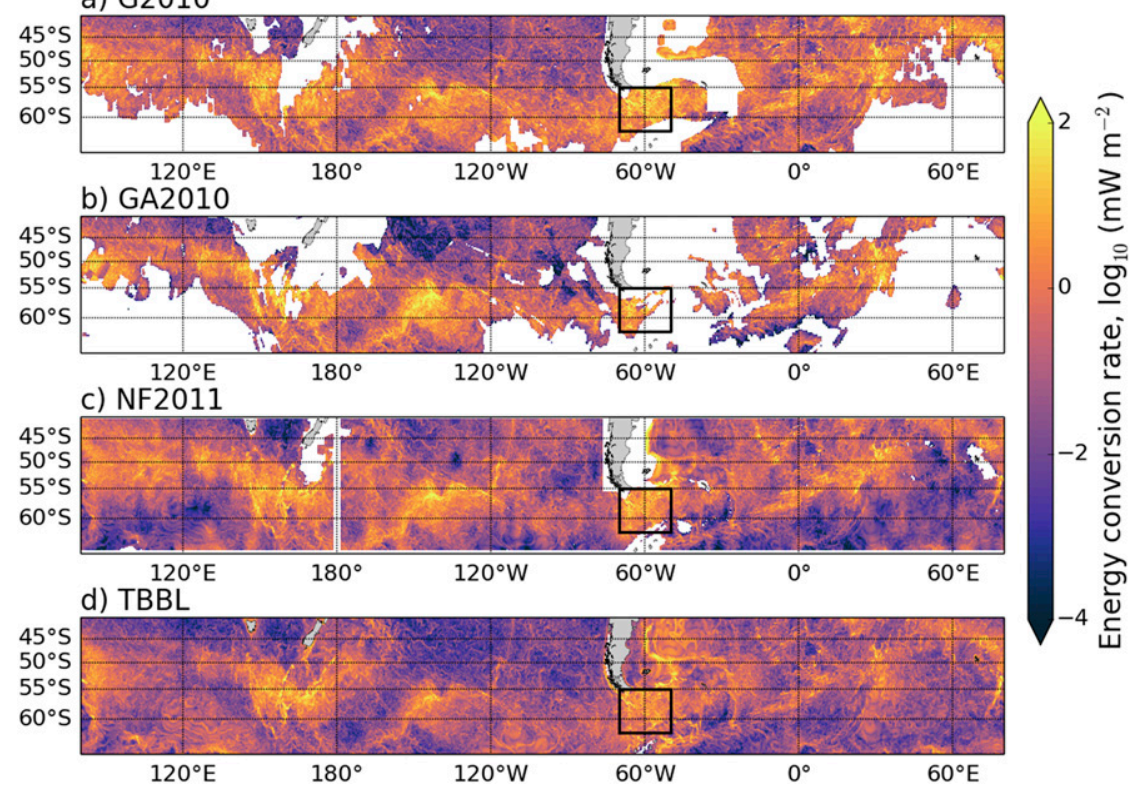

FIG. 10. Energy loss from the time-mean flow due to lee wave generation based on (a) G2010, (b) GA2010, (c) NF2011, and (d) that in the TBBL. Black boxes mark the Drake Passage where the spatial-mean energy loss from the time-mean flow is calculated.

respectively. Our estimates of spatial- and time-mean lee wave drag in the Drake Passage (marked by black boxes in Fig. 9) are 0.08 (G2010), 0.03 (GA2010), and $0.04 \mathrm{~N} \mathrm{~m}^{-2}$ (NF2011), which are consistent with those in Naveira Garabato et al. (2013) (ranging from 0.03 to $0.08 \mathrm{~N} \mathrm{~m}^{-2}$; shown in their Fig. $4 \mathrm{~b}$ ). In the same area marked in Fig. 9d, spatial- and time-mean bottom frictional drag is $0.02 \mathrm{~N} \mathrm{~m}^{-2}$. The larger offline estimate of lee wave drag implies that lee wave drag could potentially be a more important momentum sink to the mean flow than bottom frictional drag. Our finding that lee wave drag could be a more important momentum sink to the mean flow than bottom frictional drag is consistent with a similar offline analysis on the time mean lee wave drag using a different high-resolution global ocean model (Naveira Garabato et al. 2013) and with idealized, internal-wave-permitting simulations (Nikurashin et al. 2013).

We calculate the energy loss from the time-mean flow associated with lee wave generation $E_{\text {mean }}$, using G2010, GA2010, and NF2011 (Figs. 10a-c), and compare them with that from the total flow (Figs. 8a-c) as well as with the energy loss from the time-mean flow due to the bottom frictional drag in the TBBL (Fig. 10d). The energy loss from the time-mean flow due to lee wave generation based on G2010, GA2010, and NF2011 account for $24 \%(0.039 \mathrm{TW}), 24 \%(0.025 \mathrm{TW})$, and $30 \%$ $(0.030 \mathrm{TW})$ of their corresponding total component (Fig. 8) in the Southern Ocean, respectively. The Drake
Passage-averaged lee wave generation rate is $4.6,2.8$, and $2.2 \mathrm{~mW} \mathrm{~m}^{-2}$ corresponding to G2010, GA2010, and NF2011, whereas the spatial-mean energy dissipation rate in the TBBL is $1.3 \mathrm{~mW} \mathrm{~m}^{-2}$. The Southern Ocean integrals and Drake Passage-averaged values indicate that the energy loss from the time-mean flow due to lee wave generation is weaker than that from the total flow. Small energy loss associated with the time-mean flow is also reflected by a much smaller coverage of area with lee wave generation rate higher than $1 \mathrm{~mW} \mathrm{~m}^{-2}(9 \%$ in G2010, Fig. 10a; 5\% in GA2010, Fig. 10b; and 7\% in NF2011, Fig. 10c) of the Southern Ocean. The energy conversion from the time-mean flow to lee waves in all three cases exceed the energy dissipation in the TBBL, for both Southern Ocean integrals (Table 2) and Drake Passage-averaged rates. Our results show that the lee wave generation is also potentially more important than the turbulent processes in the TBBL for the energy loss from the time-mean flow, albeit weaker than that associated with the total flow.

We also evaluate the contribution of eddy velocity to the energy loss from the mean flow associated with lee wave generation and TBBL processes (Fig. 11) using Eq. (6). The results based on GA2010 and NF2011 are qualitatively similar to the one based on G2010 and hence are not shown. Our results show that transient eddies contribute $36 \%$ to the energy loss from the mean flow due to lee wave generation and $41 \%$ to that due to the bottom friction in the TBBL. The eddy contribution 
a) $\mathrm{G} 2010,-\overline{\tau(\mathbf{u})} \cdot \overline{\mathbf{u}}$

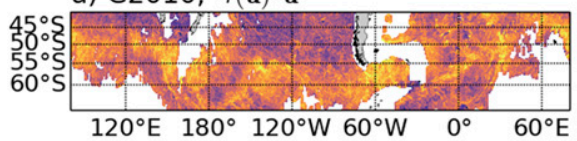

b) $\mathrm{G} 2010,-\tau(\overline{\mathbf{u}}) \cdot \overline{\mathbf{u}}$
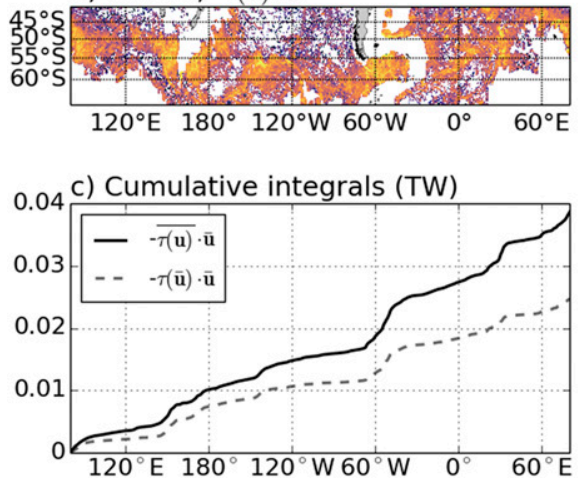

d) TBBL, $-\overline{\tau(\mathbf{u})} \cdot \overline{\mathbf{u}}$
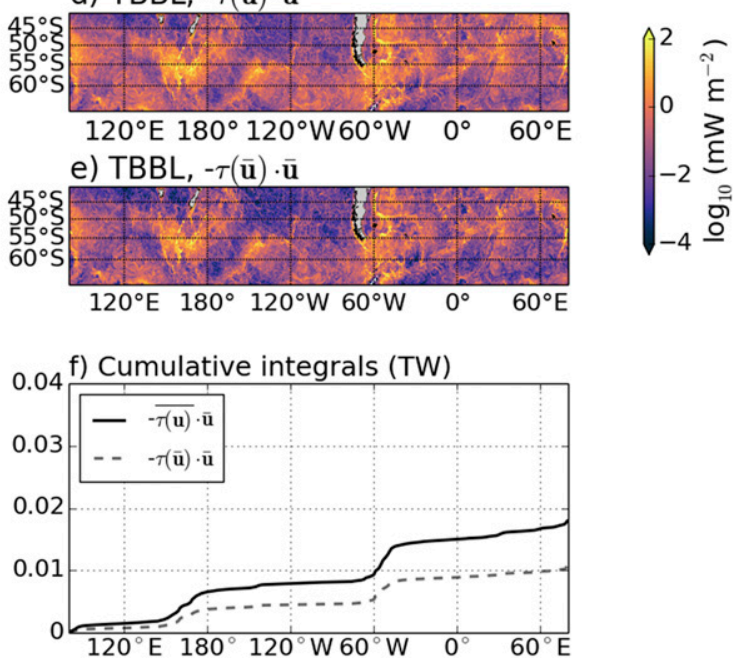

FIG. 11. (a) Energy loss from the time-mean flow due to lee wave generation. (b) Lee wave generation calculated using time-mean velocity. (c) Cumulative integrals along the longitude of (a) and (b). (d)-(f) As in (a)-(c), but for the corresponding maps for TBBL dissipation.

is likely attributed to its anisotropy (skewness; Naveira Garabato et al. 2013) and the nonlinear dependence of lee wave drag on the velocity. The fact that eddies make a significant contribution to the time-mean lee wave drag as well as the energy loss from the mean flow implies that a better representation of the eddy field in the ocean models would also improve the simulation of the mean field.

\section{c. Eddy flow}

We estimate the energy loss from the transient eddy flow associated with lee wave generation (Fig. 12b) $E_{\text {eddy }}$ and compare it to that from the time-mean flow (Fig. 12a) $E_{\text {mean }}$. Here, we only show calculations using G2010 to exemplify the partition between the mean- and eddy-generated lee waves (Figs. 12a,b). We find that lee waves get $76 \%(0.12 \mathrm{TW})$ of their energy from the transient eddy field and 24\% (0.04 TW) from the mean field. The Drake Passage-averaged energy conversion rate to lee waves from the mean and eddy flow are 4.4 and $12.7 \mathrm{~mW} \mathrm{~m}^{-2}$, respectively. The lee wave generation rate associated with the eddy flow is not only stronger than that from the time-mean flow but also takes place over a wider area in the Southern Ocean; the former is higher than $1 \mathrm{~mW} \mathrm{~m}^{-2}$ over $24 \%$ (G2010, Fig. 12b; $13 \%$ in GA2010, not shown; and 20\% in NF2011, not shown) of the Southern Ocean while the latter (aforementioned) is over $9 \%$. The domination of the eddy field in transferring energy into lee waves can be seen across a wide range of longitude over the Southern Ocean (red solid line in Fig. 12d). The large differences between the meridional sum of eddy- and mean-generated lee waves along the longitude occur at hot spots of small-scale roughness (gray shadings in Fig. 12d). In these longitude bands, lee wave generation is evidently high for each flow with respect to the background values (Figs. 12a,b). The agreement between high lee wave generation and large differences between the eddy and time-mean flow can be explained; there is a certain partition between eddy- and mean-generated lee waves so that the difference is generally a fraction $(50 \%)$ of the total lee wave generation rate. Therefore, the higher the generation, the larger the difference. This fraction is found in our calculations.

We also repeat our calculations with a larger critical steepness parameter, 0.75, as in Scott et al. (2011) and find that the energy conversion from the mean and eddy field into lee waves in the Southern Ocean increase by $64 \%$ (from 0.04 to $0.06 \mathrm{TW}$ ) and $55 \%$ (from 0.12 to $0.19 \mathrm{TW}$ ), respectively; however, the ratio between the mean versus eddy contribution remains similar (Table 3 ).

We compare the energy loss from the eddy flow due to lee wave generation (Fig. 12b) $E_{\text {eddy }}$ with that due to bottom friction (Fig. 12c). Eddies lose 0.12 TW of energy to lee waves and $0.05 \mathrm{TW}$ of energy in the TBBL over the Southern Ocean. The Drake Passage-averaged energy dissipation rate associated with lee wave generation and bottom frictional dissipation are 12.7 and $3.7 \mathrm{~mW} \mathrm{~m}^{-2}$, respectively. The energy conversion from eddies to lee waves occurs at a number of locations over a wider range of area, such as along the Southeast Indian Ridge south of Tasmania, in the Drake Passage and Scotia Sea, and along the Southwest Indian Ridge (Fig. 12b). The energy dissipation in the TBBL from the 
a) Mean to lee waves, G2010
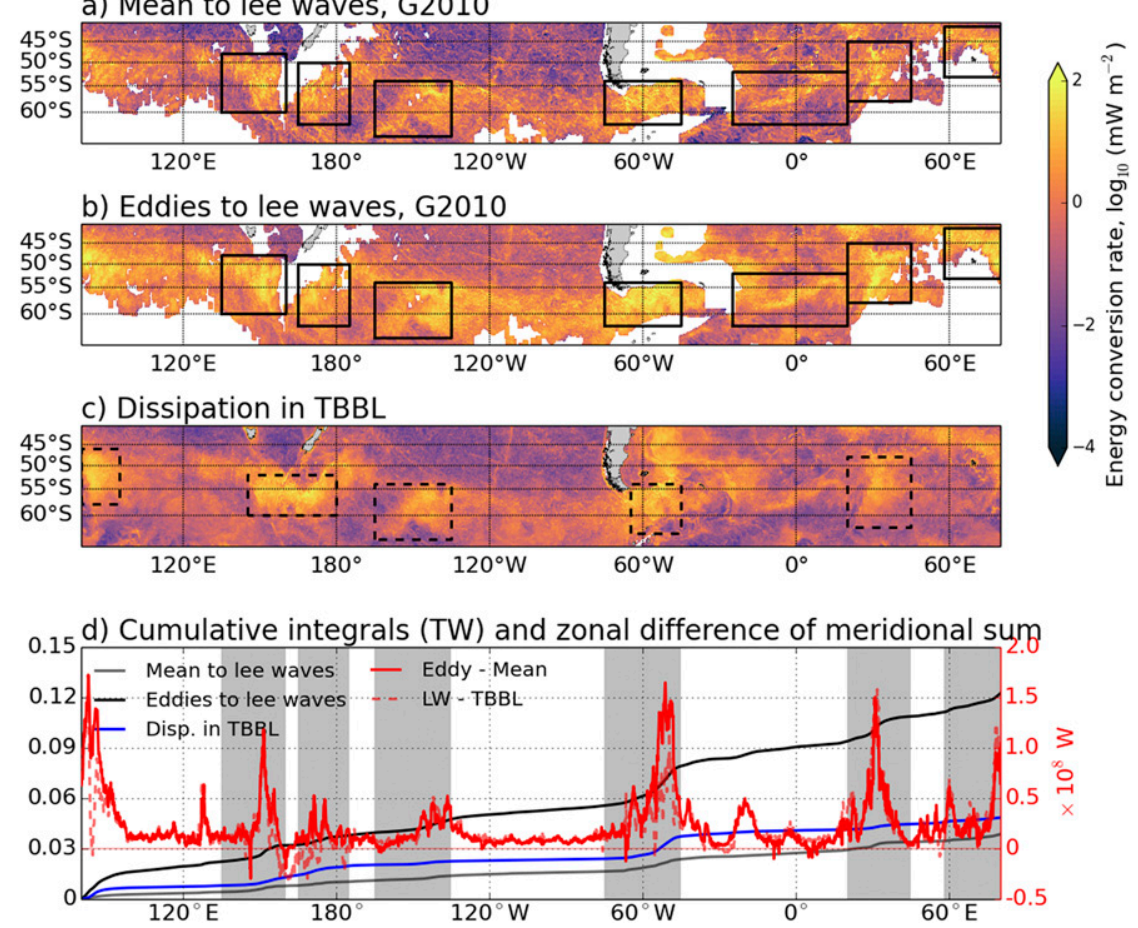

FIG. 12. Energy conversion from (a) time-mean and (b) eddy flow to lee waves using topographic parameters from G2010, (c) energy dissipation of the eddy flow in the TBBL, and (d) cumulative integrals along the longitudes of (a)-(c), and the differences between the meridional sum of energy loss from the eddy field due to lee wave generation and that from the mean field (red solid line) as well as the differences between the energy loss from the eddy field due to lee wave generation and that due to TBBL dissipation (red dashed line). Black solid boxes marked in (a) and (b) are the ones in Fig. 6 (marked as i-vii) showing hot spots of smallscale roughness. Black dashed boxes in (c) are the ones in Fig. 4 showing hot spots of total KE. The gray shadings in (d) correspond to the longitude bands of rough small-scale topography in order as in Fig. 6 except v.

eddy flow that is higher than $1 \mathrm{~mW} \mathrm{~m}^{-2}$ accounts for $14 \%$ of the Southern Ocean, which is smaller than the $24 \%$ coverage of that associated with lee waves. The energy transfer from eddies into lee waves is also larger than the energy dissipation of eddies in the TBBL across a wide range of longitude (red dashed line in Fig. 12d). Similar to the finding in Fig. 8e, the energy extraction from the eddy flow by these two mechanisms also shows big contrasts that coincide with high smallscale roughness highlighting the influence of small-scale topography on the lee wave generation by the flow.

\section{d. Role of anisotropy in small-scale topography}

We investigate the role of anisotropy in small-scale topography for the energy loss from the eddy flow due to lee wave generation by varying topography orientation $\theta_{s}$; we also test the effect of isotropic topography by setting wavenumbers in the strike $k_{s}$ and normal $k_{n}$ directions equal. In each case, we repeat the estimation of the lee wave generation from the eddy flow $E_{\text {eddy }}$ and calculate its relative change in percentage with respect to that in the original case (Fig. 13a). We choose to modify a topography dataset (e.g., G2010) that has anisotropic information to ensure that the relative change in energy loss from the eddy flow is caused only by the anisotropy. By using the G2010, GA2010, and NF2011 datasets, Trossman et al. (2015) have suggested that use of the anisotropic form of a lee wave theory could bring its predictions much closer to observations than use of its isotropic form. However, because the differences between results from G2010 (or GA2010) and NF2011 are

TABLE 3. Energy conversion rates into lee waves (critical steepness parameter: 0.75) integrated over the Southern Ocean (TW).

\begin{tabular}{lcccc}
\hline \hline & Total & Eddy & Mean & Topography \\
\hline Conversion into & 0.253 & $0.189(75 \%)$ & $0.064(25 \%)$ & G2010 \\
lee waves & 0.181 & $0.135(75 \%)$ & $0.046(25 \%)$ & GA2010 \\
& 0.101 & $0.070(69 \%)$ & $0.031(31 \%)$ & NF2011 \\
\hline
\end{tabular}


a) Eddies to lee waves, G2010

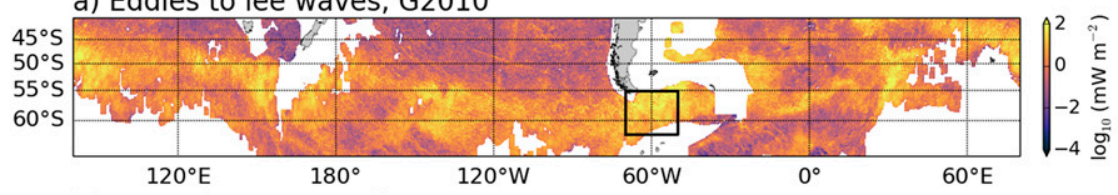

b) Isotropize topography

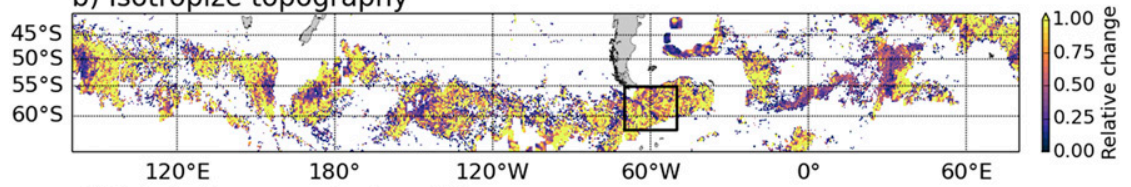

c) Rotate topography by $\mathrm{pi} / 2$

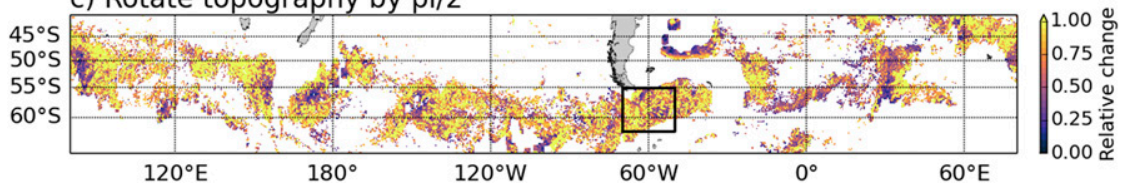

FIG. 13. (a) Energy conversion rate from eddies to lee waves calculated using G2010, and its relative change in the cases where the topography (G2010) is artificially (b) isotropized and (c) rotated for $90^{\circ}$ at each location. The area where the conversion rate is smaller than $1 \mathrm{~mW} \mathrm{~m}^{-2}$ is masked in (b) and (c) to avoid a very large relative change associated with small original conversion rate.

attributable to many factors associated with data collection and processing apart from the representation of anisotropy, we modify one dataset (e.g., G2010) to isolate the effect of anisotropy versus isotropy in the bathymetry.

Energy conversion into lee waves from the eddy field is sensitive to changes in anisotropy (Figs. 13b,c). In the isotropized case where we equalize $k_{s}$ and $k_{n}$ in G2010, the Southern Ocean-averaged relative change is $40 \%$ and the Drake Passage-averaged relative change is $43 \%$ (Fig. 13b). About $31 \%$ of the area of interest (colored part in Fig. 13b) shows a relative change that is larger than the Southern Ocean-averaged relative change $(40 \%)$. The artificial isotropization can lead to up to a factor of 10 in relative change. This finding implies that use of an anisotropic bathymetric product can partially explain the discrepancy that Waterman et al. (2014) found between theory and observations. In the rotated case where we let $\theta_{s}=\theta_{s}+90^{\circ}$, the Southern Oceanaveraged relative change is $52 \%$ and the Drake Passage-averaged relative change is $48 \%$ (Fig. 13c). About $36 \%$ of the area of interest shows a relative change that is larger than the Southern Ocean average. The relative change related to the artificial rotation can be as large as 12 . Our findings show that the artificial removal of and modification to anisotropy in small-scale topography lead to a significant change in the energy transfer from eddies to lee waves. The results suggest that the anisotropy in small-scale topography matters for the energy conversion from eddies to lee waves, in contrast to previous suggestions (NF2011).

The sensitivity of the time-mean energy loss from eddies to the anisotropy in topography is likely due to the anisotropy in the eddy field (e.g., Stewart et al. 2015). Transient eddies strike topography with varying angle and velocity magnitude. If velocities are constant while rotating in time, time-mean energy conversion from eddies to lee waves will be independent of the orientation of topography. However, if eddy velocities are correlated with the orientation of large-scale topography, time-mean energy loss from eddies to lee waves would vary with the relative angle between the major axis of an elliptical abyssal hill and that of an eddy velocity ellipse.

\section{Summary}

Transient eddies are important in the Southern Ocean for transporting tracers and regulating the sensitivity of large-scale circulation to changing climate (Rintoul and Naveira Garabato 2013, and references therein). Our knowledge of the evolution of the eddy field and its impacts are strongly limited by the fate of eddy energy. Despite the uncertain contribution of various potential eddy energy dissipation mechanisms, eddy-topography interaction is believed to play an important role in arresting the inverse energy cascade and converting eddy energy into smaller unbalanced scales, which subsequently cascade energy to dissipation scales (Marshall and Naveira Garabato 2008). Transient eddies are observed to modulate the intensity of turbulent dissipation (St. Laurent et al. 2012; Waterman et al. 2013) and mixing (e.g., Sloyan 2005; Naveira Garabato et al. 2004) over rough topography in the Southern Ocean. This modulation is likely through the generation and breaking of lee 
waves (e.g., Brearley et al. 2013; Sheen et al. 2014). Lee waves have been recognized as an energy sink for the global geostrophic flow (e.g., NF2011; Scott et al. 2011) and a momentum sink for the time-mean ACC (Naveira Garabato et al. 2013) and have been suggested to catalyze the energy conversion from eddies to turbulence (Nikurashin and Ferrari 2013). However, the energy conversion from the transient eddy field to lee waves and its importance for the energy budget of the eddy field have remained unclear.

We apply a mean-eddy decomposition to lee wave generation and find that lee waves extract energy primarily from the eddy field in the Southern Ocean (Fig. 12). Our decomposition is reliable as the lee wave generation from the total flow (Fig. 8) and time-mean lee wave drag (Fig. 9) are consistent with results in previous studies. In this study, we find that lee waves extract $0.12 \mathrm{TW}(76 \%)$ energy from the eddy field and $0.04 \mathrm{TW}(24 \%)$ from the mean field in the Southern Ocean using G2010.

We find that eddy velocity contributes to the timemean lee wave drag and energy loss from the time-mean field associated with lee wave generation. The eddy contribution to the momentum and energy balance of the mean field is nonzero when the drag is nonlinearly dependent on the velocity. The eddy contribution exists for both anisotropic (Naveira Garabato et al. 2013) and isotropic eddy fields. The reason is that it is the lee waves generated by total flow, rather than time-mean flow itself, that apply a drag on the time-mean flow. The implication is that the representation of the time-mean flow would also benefit from a better-simulated eddy flow, especially in coarse and eddy-permitting models where eddies are not explicitly and completely resolved.

We compare the relative contribution of lee waves with that of TBBL processes to the energy dissipation of the eddy field and conclude that lee wave generation is an important dissipation mechanism for the eddy field in the Southern Ocean. While the transient eddy field in the Southern Ocean can be dissipated by both the generation of lee waves at rough topography and turbulence in the TBBL, the dissipation rate due to the lee wave generation $(0.12 \mathrm{TW})$ exceeds that due to TBBL processes $(0.05 \mathrm{TW})$. Lee wave generation is shown to be important for a larger area in the Southern Ocean than TBBL processes. The difference in spatial distribution highlights the role of roughness in small-scale topography for transferring energy from eddies to lee waves. Considering the unique role that eddies play in Southern Ocean circulation, it is of great importance to improve the energetics of eddy field in eddy-resolving global ocean models by parameterizing unresolved lee waves that leads to eddy energy dissipation.
The anisotropy in small-scale topography was assumed to be unimportant for the energy conversion from eddies to lee waves (NF2011). The decomposition allows us to explore the sensitivity of energy loss from eddies due to lee wave generation to anisotropy in smallscale topography. We find that artificially isotropizing and rotating topography lead to over a $40 \%$ change in the energy loss from the eddy field. This is likely due to the anisotropy in the eddy field (Stewart et al. 2015).

Our offline estimation is a first step at evaluating the importance of lee wave generation to eddy energy loss near the seafloor. One caveat on this calculation is that the global model we use does not include lee waves. Nevertheless, we use near-bottom velocity and stratification fields from MOM5-SIS because they are a good representation of those in the Southern Ocean. We acknowledge that the good agreement found between model data and two mooring measurements at two locations cannot guarantee good agreement in the rest of the Southern Ocean; however, we found the comparison sufficiently encouraging for us to use model data in our estimation. We believe our estimation of energy transfer from eddies to lee waves is robust and can be reproduced by another global eddy-resolving ocean model with or without lee waves, as long as the modeled near-bottom eddy velocity and stratification compare reasonably well to those observed. The parameterization of lee waves in eddy-resolving global ocean models (Trossman et al. 2013, 2016) might result in a quantitative difference and a spatial shift of hot spots in near-bottom eddy velocity and stratification fields, as lee wave drag slows down and deflects resolved flow. However, models with lee waves can still be tuned to reach an equilibrium where the bottom eddy velocity is close to observed values. We expect that a similar eddy velocity field to what we have used here will give a similar energy conversion from the eddy field to lee waves.

Our results clearly show that the energy extraction from the eddy flow by lee waves in the Southern Ocean is significant and should be represented in eddyresolving global ocean models to improve the energy equilibration of the eddy flow. The generation of lee waves is demonstrated to be a significant energy sink for the Southern Ocean eddy flow. Accounting for lee waves in eddy-resolving global ocean models will improve the simulated eddy field, which regulates the lee wave generation, the momentum and energy balance of the mean field, and the sensitivity of the ACC and MOC under the changing climate. Melet et al. (2014) showed that the ocean stratification and MOC were significantly altered by a lee-wavedriven mixing parameterization based on NF2011 in a climate model. Melet et al. (2015) found that the energy 
flux into lee waves may change over time under climate conditions. However, most global ocean and climate models used to study eddy saturation and eddy compensation (e.g., Farneti et al. 2015; Bishop et al. 2016) neither resolve lee waves nor consider the energy dissipation of the eddy flow due to the lee wave generation. In the absence of a dynamical link involving wind, eddies, stratification, lee waves, and topography, the modulation of eddies on the sensitivity of the Southern Ocean circulation as wind changes might be inaccurate. The necessity to consider lee waves in the Southern Ocean sensitivity study has been suggested by observational evidence along a hydrographic transect in the Drake Passage (Sheen et al. 2014), where abyssal mixing is shown to be modulated by mesoscale eddies through the breaking of lee waves generated as eddies interacting with rough topography. Sheen et al. (2014) suggest that a dynamic linking eddies with mixing through lee waves is common to all ACC regions where rough topography is present. Our results provide a quantitative evidence that lee waves effectively weaken the eddy flow in the Southern Ocean. The implication is that the effects of (unresolved) lee waves on the (resolved) eddy flow should be included in eddy-resolving ocean models in a self-regulating way to study the sensitivity of the Southern Ocean circulation to changes in wind.

Acknowledgments. This research was undertaken on the NCI National Facility in Canberra, Australia, which is supported by the Australian Government. LY was supported by the joint CSIRO-UTAS QMS program. MN was supported by the Australian Research Council (ARC) Discovery Early Career Research Award (DECRA) Fellowship (DE150100937). We thank John Goff and Brian Arbic for providing their abyssal hill topography products. We thank Alberto Naveira Garabato for providing access to the DIMES mooring data. BMS provided the SOFine mooring data. We also thank two anonymous reviewers for their comments and suggestions.

\section{REFERENCES}

Abernathey, R., J. Marshall, and D. Ferreira, 2011: The dependence of Southern Ocean meridional overturning on wind stress. J. Phys. Oceanogr., 41, 2261-2278, https://doi.org/ 10.1175/JPO-D-11-023.1.

Arbic, B. K., and Coauthors, 2009: Estimates of bottom flows and bottom boundary layer dissipation of the oceanic general circulation from global high-resolution models. J. Geophys. Res., 114, C02024, https://doi.org/10.1029/2008JC005072.

Bell, T. H., 1975: Topographically generated internal waves in the open ocean. J. Geophys. Res., 80, 320-327, https://doi.org/ 10.1029/JC080i003p00320.
Bishop, S. P., P. R. Gent, F. O. Bryan, A. F. Thompson, M. C. Long, and R. Abernathey, 2016: Southern Ocean overturning compensation in an eddy-resolving climate simulation. J. Phys. Oceanogr., 46, 1575-1592, https://doi.org/10.1175/ JPO-D-15-0177.1.

Böning, C. W., A. Dispert, M. Visbeck, S. R. Rintoul, and F. U. Schwarzkopf, 2008: The response of the Antarctic Circumpolar Current to recent climate change. Nat. Geosci., 1, 864869, https://doi.org/10.1038/ngeo362.

Brearley, J. A., K. L. Sheen, A. C. Naveira Garabato, D. A. Smeed, and S. Waterman, 2013: Eddy-induced modulation of turbulent dissipation over rough topography in the Southern Ocean. J. Phys. Oceanogr., 43, 2288-2308, https://doi.org/10.1175/ JPO-D-12-0222.1.

Bühler, O., and M. E. McIntyre, 2005: Wave capture and wavevortex duality. J. Fluid Mech., 534, 67-95, https://doi.org/ 10.1017/S0022112005004374.

de Lavergne, C., G. Madec, J. Le Sommer, A. J. G. Nurser, and A. C. Naveira Garabato, 2016: On the consumption of Antarctic Bottom Water in the abyssal ocean. J. Phys. Oceanogr., 46, 635-661, https://doi.org/10.1175/JPO-D-14-0201.1.

Dufour, C. O., L. L. Sommer, J. D. Zika, M. Gehlen, J. C. Orr, P. Mathiot, and B. Barnier, 2012: Standing and transient eddies in the response of the Southern Ocean meridional overturning to the southern annular mode. J. Climate, 25, 6958-6974, https://doi.org/10.1175/JCLI-D-11-00309.1.

Farneti, R., T. L. Delworth, A. J. Rosati, S. M. Griffies, and F. Zeng, 2010: The role of mesoscale eddies in the rectification of the Southern Ocean response to climate change. J. Phys. Oceanogr., 40, 1539-1557, https://doi.org/10.1175/ 2010JPO4353.1.

— , and Coauthors, 2015: An assessment of Antarctic Circumpolar Current and Southern Ocean meridional overturning circulation during 1958-2007 in a suite of interannual CORE-II simulations. Ocean Modell., 93, 84-120, https://doi.org/10.1016/ j.ocemod.2015.07.009.

Ferrari, R., and C. Wunsch, 2009: Ocean circulation kinetic energy: Reservoirs, sources, and sinks. Annu. Rev. Fluid Mech., 41, 253282, https://doi.org/10.1146/annurev.fluid.40.111406.102139.

Gill, A. E., 1982: Atmosphere-Ocean Dynamics. Academic Press, $662 \mathrm{pp}$.

_ J. S. Green, and A. J. Simmons, 1974: Energy partition in the large-scale ocean circulation and the production of mid-ocean eddies. Deep-Sea Res., 21, 499-528, https://doi.org/10.1016/ 0011-7471(74)90010-2.

Goff, J. A., 2010: Global prediction of abyssal hill root-mean-square heights from small-scale altimetric gravity variability. J. Geophys. Res., 115, B12104, https://doi.org/10.1029/2010JB007867.

_ morphology: Inversion of sea beam data for second-order statistics. J. Geophys. Res., 93, 13 589-13 608, https://doi.org/ 10.1029/JB093iB11p13589.

, and - 1989: Stochastic modeling of seafloor morphology: A parameterized Gaussian model. Geophys. Res. Lett., 16, 45-48, https://doi.org/10.1029/GL016i001p00045.

— roughness statistics for use in ocean models from digital maps of paleo-spreading rate, paleo-ridge orientation, and sediment thickness. Ocean Modell., 32, 36-43, https://doi.org/10.1016/ j.ocemod.2009.10.001.

Griffies, S. M., 2012: Elements of the Modular Ocean Model (MOM): 2012 release. NOAA/GFDL Ocean Group Tech. Rep. 7, 620 pp. 
- and Coauthors, 2015: Impacts on ocean heat from transient mesoscale eddies in a hierarchy of climate models. J. Climate, 28, 952-977, https://doi.org/10.1175/JCLI-D-14-00353.1.

Hallberg, R., and A. Gnanadesikan, 2006: The role of eddies in determining the structure and response of the wind-driven Southern Hemisphere overturning: Results from the Modeling Eddies in the Southern Ocean (MESO) project. J. Phys. Oceanogr., 36, 2232-2252, https://doi.org/10.1175/JPO2980.1.

Heywood, K. J., A. C. Naveira Garabato, and D. P. Stevens, 2002: High mixing rates in the abyssal Southern Ocean. Nature, 415, 1011-1014, https://doi.org/10.1038/4151011a.

Hogg, A. M., W. K. Dewar, P. Berloff, and M. L. Ward, 2011: Kelvin wave hydraulic control induced by interactions between vortices and topography. J. Fluid Mech., 687, 194-208, https://doi.org/10.1017/jfm.2011.344.

— M. P. Meredith, D. P. Chambers, E. P. Abrahamsen, C. W. Hughes, and A. K. Morrison, 2015: Recent trends in the Southern Ocean eddy field. J. Geophys. Res. Oceans, 120, 257-267, https://doi.org/10.1002/2014JC010470.

Kunze, E., E. Firing, J. M. Hummon, T. K. Chereskin, and A. M. Thurnherr, 2006: Global abyssal mixing inferred from lowered ADCP shear and CTD strain profiles. J. Phys. Oceanogr., 36, 1553-1576, https://doi.org/10.1175/JPO2926.1.

Liang, X., and A. M. Thurnherr, 2012: Eddy-modulated internal waves and mixing on a midocean ridge. J. Phys. Oceanogr., 42, 1242-1248, https://doi.org/10.1175/JPO-D-11-0126.1.

Marshall, D. P., and A. C. Naveira Garabato, 2008: A conjecture on the role of bottom-enhanced diapycnal mixing in the parameterization of geostrophic eddies. J. Phys. Oceanogr., 38, 1607-1613, https://doi.org/10.1175/2007JPO3619.1.

_ J. R. Maddison, and P. S. Berloff, 2012: A framework for parameterizing eddy potential vorticity fluxes. J. Phys. Oceanogr., 42, 539-557, https://doi.org/10.1175/JPO-D-11-048.1.

Melet, A., R. Hallberg, S. Legg, and M. Nikurashin, 2014: Sensitivity of the ocean state to lee wave-driven mixing. J. Phys. Oceanogr., 44, 900-921, https://doi.org/10.1175/JPO-D-13-072.1.

,,-- A. Adcroft, M. Nikurashin, and S. Legg, 2015: Energy flux into internal lee waves: Sensitivity to future climate changes using linear theory and a climate model. J. Climate, 28, 2365-2384, https://doi.org/10.1175/JCLI-D-14-00432.1.

Meredith, M. P., 2011: Cruise report: RRS James Cook JC054 (DIMES UK2). British Antarctic Survey Cruise Rep. 2593, $206 \mathrm{pp}$.

—, and A. M. Hogg, 2006: Circumpolar response of Southern Ocean eddy activity to a change in the southern annular mode. Geophys. Res. Lett., 33, L16608, https://doi.org/10.1029/ 2006 GL026499.

Meyer, A., B. M. Sloyan, K. L. Polzin, H. E. Phillips, and N. L. Bindoff, 2015: Mixing variability in the Southern Ocean. J. Phys. Oceanogr., 45, 966-987, https://doi.org/10.1175/JPO-D-14-0110.1.

— K. L. Polzin, B. M. Sloyan, and H. E. Phillips, 2016: Internal waves and mixing near the Kerguelen Plateau. J. Phys. Oceanogr., 46, 417-437, https://doi.org/10.1175/JPO-D-15-0055.1.

Molemaker, M. J., J. C. McWilliams, and I. Yavneh, 2005: Baroclinic instability and loss of balance. J. Phys. Oceanogr., 35, 1505-1517, https://doi.org/10.1175/JPO2770.1.

Morrison, A. K., and A. M. Hogg, 2013: On the relationship between Southern Ocean overturning and ACC transport. J. Phys. Oceanogr., 43, 140-148, https://doi.org/10.1175/ JPO-D-12-057.1.

Munday, D. R., H. L. Johnson, and D. P. Marshall, 2013: Eddy saturation of equilibrated circumpolar currents. J. Phys. Oceanogr., 43, 507-532, https://doi.org/10.1175/JPO-D-12-095.1.
Naveira Garabato, A. C., 2009: RRS James Cook cruise 29: 01 Nov22 Dec 2008. National Oceanography Centre Cruise Rep. 35, 220 pp., https://eprints.soton.ac.uk/65884/1/nocscr035.pdf.

- 2010: RRS James Cook Cruise 41: 05-21 Dec 2009. National Oceanography Centre Cruise Rep. 56, 168 pp., https://eprints. soton.ac.uk/167561/1/nocscr056.pdf.

— K. L. Polzin, B. A. King, K. J. Heywood, and M. Visbeck, 2004: Widespread intense turbulent mixing in the Southern Ocean. Science, 303, 210-213, https://doi.org/10.1126/ science.1090929.

— A. J. G. Nurser, R. B. Scott, and J. A. Goff, 2013: The impact of small-scale topography on the dynamical balance of the ocean. J. Phys. Oceanogr., 43, 647-668, https://doi.org/10.1175/ JPO-D-12-056.1.

Nikurashin, M., and R. Ferrari, 2010a: Radiation and dissipation of internal waves generated by geostrophic motions impinging on small-scale topography: Application to the Southern Ocean. J. Phys. Oceanogr., 40, 2025-2042, https://doi.org/ 10.1175/2010JPO4315.1.

$\longrightarrow$, and $-2010 \mathrm{~b}$ : Radiation and dissipation of internal waves generated by geostrophic motions impinging on small-scale topography: Theory. J. Phys. Oceanogr., 40, 1055-1074, https:// doi.org/10.1175/2009JPO4199.1.

$\longrightarrow$, and — 2011: Global energy conversion rate from geostrophic flows into internal lee waves in the deep ocean. Geophys. Res. Lett., 38, L08610, https://doi.org/10.1029/ 2011GL046576.

— , and — 2013: Overturning circulation driven by breaking internal waves in the deep ocean. Geophys. Res. Lett., 40, 3133-3137, https://doi.org/10.1002/grl.50542.

— G. K. Vallis, and A. Adcroft, 2013: Routes to energy dissipation for geostrophic flows in the Southern Ocean. Nat. Geosci., 6, 48-51, https://doi.org/10.1038/ngeo1657.

- R. Ferrari, N. Grisouard, and K. Polzin, 2014: The impact of finite-amplitude bottom topography on internal wave generation in the Southern Ocean. J. Phys. Oceanogr., 44, 29382950, https://doi.org/10.1175/JPO-D-13-0201.1.

Olbers, D., D. Borowski, C. Völker, and J.-O. Wölff, 2004: The dynamical balance, transport and circulation of the Antarctic Circumpolar Current. Antarct. Sci., 16, 439-470, https:// doi.org/10.1017/S0954102004002251.

Polzin, K. L., 2008: Mesoscale eddy-internal wave coupling. Part I: Symmetry, wave capture, and results from the Mid-Ocean Dynamics Experiment. J. Phys. Oceanogr., 38, 2556-2574, https://doi.org/10.1175/2008JPO3666.1.

— J. J. Toole, J. R. Ledwell, and R. W. Schmitt, 1997: Spatial variability of turbulent mixing in the abyssal ocean. Science, 276, 93-96, https://doi.org/10.1126/science.276.5309.93.

Rintoul, S. R., and A. C. Naveira Garabato, 2013: Dynamics of the Southern Ocean circulation. Ocean Circulation and Climate: $A$ 21st Century Perspective, G. Siedler et al., Eds., International Geophysics Series, Vol. 103, Academic Press, 471-492, https:// doi.org/10.1016/B978-0-12-391851-2.00018-0.

Scott, R. B., B. K. Arbic, E. P. Chassignet, A. C. Coward, M. Maltrud, W. J. Merryfield, A. Srinivasan, and A. Varghese, 2010: Total kinetic energy in four global eddying ocean circulation models and over 5000 current meter records. Ocean Modell., 32, 157-169, https://doi.org/10.1016/ j.ocemod.2010.01.005.

, J. A. Goff, A. C. Naveira Garabato, and A. J. Nurser, 2011: Global rate and spectral characteristics of internal gravity wave generation by geostrophic flow over topography. J. Geophys. Res., 116, C09029, https://doi.org/10.1029/2011JC007005. 
Sen, A., R. B. Scott, and B. K. Arbic, 2008: Global energy dissipation rate of deep-ocean low-frequency flows by quadratic bottom boundary layer drag: Computations from current-meter data. Geophys. Res. Lett., 35, L09606, https://doi.org/10.1029/ 2008 GL033407.

Sheen, K. L., and Coauthors, 2013: Rates and mechanisms of turbulent dissipation and mixing in the Southern Ocean: Results from the Diapycnal and Isopycnal Mixing Experiment in the Southern Ocean (DIMES). J. Geophys. Res. Oceans, 118, 2774-2792, https://doi.org/10.1002/ jgrc. 20217.

__ , and Coauthors, 2014: Eddy-induced variability in Southern Ocean abyssal mixing on climatic timescales. Nat. Geosci., 7 , 577-582, https://doi.org/10.1038/ngeo2200.

Sloyan, B. M., 2005: Spatial variability of mixing in the Southern Ocean. Geophys. Res. Lett., 32, L18603, https://doi.org/10.1029/ 2005GL023568.

Smith, W. H., and D. T. Sandwell, 1997: Global sea floor topography from satellite altimetry and ship depth soundings. Science, 277, 1956-1962, https://doi.org/10.1126/science.277.5334.1956.

Stewart, K. D., P. Spence, S. Waterman, J. L. Sommer, J. M. Molines, J. M. Lilly, and M. H. England, 2015: Anisotropy of eddy variability in the global ocean. Ocean Modell., 95, 53-65, https://doi.org/10.1016/j.ocemod.2015.09.005.

— , A. M. Hogg, S. M. Griffies, A. P. Heerdegen, M. L. Ward, P. Spence, and M. H. England, 2017: Vertical resolution of baroclinic modes in global ocean models. Ocean Modell., 113, 50-65, https://doi.org/10.1016/j.ocemod.2017.03.012.

St. Laurent, L., A. C. Naveira Garabato, J. R. Ledwell, A. M. Thurnherr, J. M. Toole, and A. J. Watson, 2012: Turbulence and diapycnal mixing in Drake Passage. J. Phys. Oceanogr., 42, 2143-2152, https://doi.org/10.1175/JPO-D-12-027.1.

Thompson, D. W., and S. Solomon, 2002: Interpretation of recent Southern Hemisphere climate change. Science, 296, 895-899, https://doi.org/10.1126/science.1069270.
Trossman, D. S., B. K. Arbic, S. T. Garner, J. A. Goff, S. R. Jayne, E. J. Metzger, and A. J. Wallcraft, 2013: Impact of parameterized lee wave drag on the energy budget of an eddying global ocean model. Ocean Modell., 72, 119-142, https://doi.org/10.1016/ j.ocemod.2013.08.006.

— S. Waterman, K. L. Polzin, B. K. Arbic, S. T. Garner, A. C. Naveira-Garabato, and K. L. Sheen, 2015: Internal lee wave closures: Parameter sensitivity and comparison to observations. J. Geophys. Res. Oceans, 120, 7997-8019, https://doi.org/ 10.1002/2015JC010892.

— B. K. Arbic, J. G. Richman, S. T. Garner, S. R. Jayne, and A. J. Wallcraft, 2016: Impact of topographic internal lee wave drag on an eddying global ocean model. Ocean Modell., 97, 109-128, https://doi.org/10.1016/j.ocemod.2015.10.013.

Waterman, S., A. C. Naveira Garabato, and K. L. Polzin, 2013: Internal waves and turbulence in the Antarctic Circumpolar Current. J. Phys. Oceanogr., 43, 259-282, https://doi.org/10.1175/ JPO-D-11-0194.1.

K. L. Polzin, A. C. Naveira Garabato, K. L. Sheen, and A. Forryan, 2014: Suppression of internal wave breaking in the Antarctic Circumpolar Current near topography. J. Phys. Oceanogr., 44, 1466-1492, https://doi.org/10.1175/ JPO-D-12-0154.1.

Watson, A. J., J. R. Ledwell, M. J. Messias, B. A. King, N. Mackay, M. P. Meredith, B. Mills, and A. C. Naveira Garabato, 2013: Rapid cross-density ocean mixing at mid-depths in the Drake Passage measured by tracer release. Nature, 501, 408-411, https://doi.org/10.1038/nature12432.

Wright, C. J., R. B. Scott, P. Ailliot, and D. Furnival, 2014: Lee wave generation rates in the deep ocean. Geophys. Res. Lett., 41, 2434-2440, https://doi.org/10.1002/2013GL059087.

Wu, L., Z. Jing, S. Riser, and M. Visbeck, 2011: Seasonal and spatial variations of Southern Ocean diapycnal mixing from Argo profiling floats. Nat. Geosci., 4, 363-366, https://doi.org/ 10.1038/ngeo1156. 